\title{
A Case Study of Observed and Modeled Barrier Flow in the Denmark Strait in May 2015 0
}

\author{
Alice K. DuVivieR ${ }^{\mathrm{a}}$ \\ Cooperative Institute for Research in Environmental Sciences, University of Colorado Boulder, Boulder, Colorado \\ JOHN J. CASSANO \\ Cooperative Institute for Research in Environmental Sciences, and Department of Atmospheric and \\ Oceanic Sciences, University of Colorado Boulder, Boulder, Colorado \\ STEVEN GRECO AND G. DAVID EMMITT \\ Simpson Weather Associates, Charlottesville, Virginia
}

(Manuscript received 6 October 2016, in final form 2 February 2017)

\begin{abstract}
Mesoscale barrier jets in the Denmark Strait are common in winter months and have the capability to influence open ocean convection. This paper presents the first detailed observational study of a summertime (21 May 2015) barrier wind event in the Denmark Strait using dropsondes and observations from an airborne Doppler wind lidar (DWL). The DWL profiles agree well with dropsonde observations and show a vertically narrow ( $\sim 250-400 \mathrm{~m}$ ) barrier jet of $23-28 \mathrm{~m} \mathrm{~s}^{-1}$ near the Greenland coast that broadens $(\sim 300-1000 \mathrm{~m})$ and strengthens farther off coast. In addition, otherwise identical regional high-resolution Weather Research and Forecasting (WRF) Model simulations of the event are analyzed at four horizontal grid spacings (5, 10, 25, and $50 \mathrm{~km}$ ), two vertical resolutions (40 and 60 levels), and two planetary boundary layer (PBL) parameterizations [Mellor-Yamada-Nakanishi-Niino, version 2.5 (MYNN2.5) and University of Washington (UW)] to determine what model configurations best simulate the observed jet structure. Comparison of the WRF simulations with wind observations from satellites, dropsondes, and the airborne DWL scans indicate that the combination of both high horizontal resolution $(5 \mathrm{~km})$ and vertical resolution (60 levels) best captures observed barrier jet structure and speeds as well as the observed cloud field, including some convective clouds. Both WRF PBL schemes produced reasonable barrier jets with the UW scheme slightly outperforming the MYNN2.5 scheme. However, further investigation at high horizontal and vertical resolution is needed to determine the impact of the WRF PBL scheme on surface energy budget terms, particularly in the high-latitude maritime environment around Greenland.
\end{abstract}

\section{Introduction}

The seas around Greenland's southeastern coast are among the windiest locations in the World Ocean, and the Denmark Strait, in particular, is the fourth windiest location on an annual basis at the ocean's surface

Supplemental information related to this paper is available at the Journals Online website: http://dx.doi.org/10.1175/ MWR-D-16-0386.s1.

${ }^{\text {a }}$ Current affiliation: National Center for Atmospheric Research, Boulder, Colorado.

Corresponding author: Alice K. DuVivier, duvivier@ucar.edu
(Sampe and Xie 2007). Interaction between synoptic storms and southeast Greenland's steep topography (Fig. 1) drive mesoscale winds such as westerly and northeasterly tip jets near Cape Farewell and barrier winds parallel to the coastline from the Denmark Strait to Cape Farewell (Doyle and Shapiro 1999; Moore 2003; Moore and Renfrew 2005; Moore 2012).

Though possible during any season, the aforementioned types of wind events are most common in winter, and in the Denmark Strait barrier winds exceeding $20 \mathrm{~m} \mathrm{~s}^{-1}$ occur once per week on average (Harden et al. 2011). The strong barrier winds in the Denmark Strait are collocated with regions of particularly steep coastal topography, and are forced by a combination of mountain 

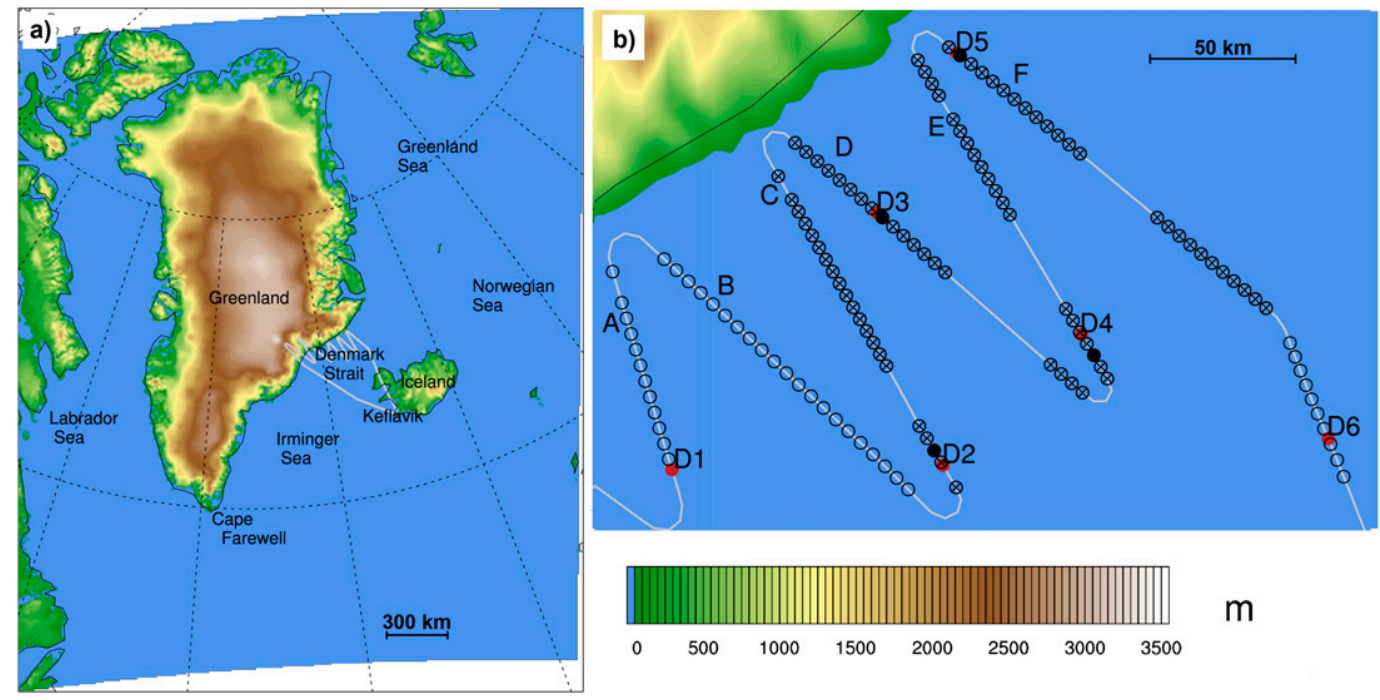

$\mathrm{m}$

FIG. 1. (a) Topography (m) in the WRF domain for simulations in Greenland region. The aircraft track on 21 May 2015 is in shown in gray. (b) The aircraft track in the Denmark Strait (gray); DAWN lidar profile locations (black circles); DAWN lidar profiles along flight legs C, D, E, and F used in vertical cross sections (black circle with cross); DAWN lidar profiles compared to dropsondes (filled black circle); and dropsonde locations (red circles with labels D1-D6).

waves and flow acceleration like that in of a corner jet (Harden and Renfrew 2012; Moore 2012; Barstad and Grønås 2005; Nigro et al. 2012). Because higherresolution models have more realistic terrain, previous modeling studies of barrier wind events show that highresolution $(10-50 \mathrm{~km})$ regional simulations tend to simulate significantly stronger winds than lower-resolution reanalyses (DuVivier and Cassano 2013; Bromwich et al. 2016; Moore et al. 2016, 2015; Hughes and Cassano 2015). Yet even at $10-15-\mathrm{km}$ grid spacing some features remain unresolved.

During winter, barrier winds result in localized maxima of oceanic surface energy loss due to large turbulent heat fluxes that dominate the surface energy budget (DuVivier et al. 2016; Harden et al. 2011). This wintertime energy loss can impact the ocean's meridional overturning circulation (Bacon et al. 2003; Pickart et al. 2003; Våge et al. 2011; de Jong et al. 2012; de Jong and de Steur 2016). Radiative fluxes are expected to dominate the surface energy budget during summer months, but little research has been done to characterize summer barrier flow in this region. Thus, comparing the summer barrier event of this study and previously studied winter barrier wind events may lead to a better understanding of how strong near-surface winds are represented in models across all seasons, what model characteristics are necessary to simulate these types of flow, and an understanding of the mechanisms that drive the winds.

Land-based automatic weather stations often record wind regimes that are dominated by the local terrain and not representative of winds that occur over the ocean (Moore et al. 2015). One buoy has been deployed just east of Cape Farewell for 6 months before it was blown off its mooring, but it showed that there may be high speed biases in satellite wind products (Moore et al. 2008). In November 2003 an airborne Doppler wind lidar (DWL) was used during the Atlantic THORPEX regional campaign to observe a westerly tip jet to the southeast of Greenland (Dörnbrack et al. 2004; Weissmann et al. 2005). The Greenland Flow Distortion Experiment (GFDex) field campaign, which took place in February 2007 (Renfrew et al. 2008), directly observed wintertime terrain-driven flow and characterized the dynamics of these types of flow. The Norwegian International Polar Year (IPY)-THORPEX campaign in winter 2008 used DWL to study polar lows and fronts northeast of Norway and included a few flights near Greenland and Iceland to study orographic flows (Kristjánsson et al. 2011).

In May 2015, NASA sponsored the second of two airborne field campaigns, collectively called Polar Winds, designed to fly the Doppler Aerosol Wind (DAWN) lidar to take airborne wind measurements of the arctic atmosphere, particularly over and off the coast of Greenland (Greco et al. 2016). The May 2015 campaign, which included 10 individual missions, was based in Keflavik, Iceland, and flew DAWN on board the NASA DC-8 aircraft along with the Yankee Environmental Systems (YES) dropsonde system. The scientific objectives of the Polar Winds campaigns included 
making model-observation comparisons in all flights and investigating coastal katabatic flows, tip jets, and barrier winds. Because of clouds, high winds, and logistics, there was only one barrier winds mission flown. The aircraft observations presented here, including both DAWN and dropsondes, were taken on 21 May 2015 and provide the first summer observations of a barrier jet in the Denmark Strait.

This paper will use the DAWN lidar, dropsonde, and satellite observations of the barrier wind observed on 21 May 2015 from approximately 1900 to 2200 UTC. Our focus is to use these observations to evaluate how well high-resolution regional simulations with the Weather Research and Forecasting (WRF) Model can reproduce the observed features with different horizontal and vertical resolutions and with two different boundary layer parameterizations. As such, we will not focus on diagnosing the dynamics that create the observed barrier wind event nor discuss other flights that took place during the campaign. Our motivation in evaluating WRF is in the context of the Regional Arctic System Model (RASM) project, which seeks to simulate mesoscale features of importance for coupled polar climate processes (DuVivier et al. 2016; Roberts et al. 2015; Cassano et al. 2017). Section 2 will describe the data and models used in this study. We describe the observations of the barrier wind in section 3 . In section 4 we compare the models with satellite surface winds, dropsondes, DAWN flight legs, and satellite observed clouds, and we will focus on the importance of horizontal and vertical resolution and planetary boundary layer (PBL) scheme on the simulated barrier flow. We discuss the results of this work and implications for future work in section 5 .

\section{Data}

\section{a. Flight observations}

DAWN has previously flown on the NASA DC-8 during the 2010 Genesis and Rapid Intensification Processes (GRIP) field project (Kavaya et al. 2014) and on the NASA C-12 for wind field characterizations off the coast of Virginia. The lidar has a pulse wavelength of $2.05 \mu \mathrm{m}$, a pulse energy of $100 \mathrm{~mJ}$, and a pulse rate of $5 \mathrm{~Hz}$ (Kavaya et al. 2014; Greco et al. 2016). DAWN is a coherent detection lidar with a downward-pointing scanner that performs a 5 angle scan $\left(-45^{\circ},-22.5^{\circ}\right.$, $0^{\circ},+22.5^{\circ}$, and $+45^{\circ}$ ) to compute each wind profile and assumes horizontal homogeneity within 150-m layers. The profiles of the horizontal wind and components are determined by a least squares fit to three to five individual DWL line-of-sight (LOS). Depending on the scanning strategies used, vertical profiles of the wind were computed every 5-7 km. Over the whole campaign the precision of both the individual LOS measurements and the computed horizontal wind components/profiles was measured to be $<1 \mathrm{~m} \mathrm{~s}^{-1}$ based upon surface returns from the ice. Most of the precision error was attributed to small uncertainties in navigation and attitude data provided by the instrument's global positioning and inertial navigation systems (GPS/INS).

The DAWN wind data presented in this paper are the first summertime airborne DWL observations of a barrier wind near Greenland and occurred on 21 May 2015 (henceforth all dates presented refer to 2015). Six dropsondes (Fig. 1b, red circles) also provide observed wind speed and direction, temperature, and humidity profiles of the barrier wind in the Denmark Strait and are labeled based on the order in which they were dropped (D1-D6) at the following UTC (hhmm:ss) times: 1946:25, 2010:31, 2030:04, 2044:11, 2059:09, and 2118:45. During the section of the flight focused on barrier wind observations, 127 DAWN profiles (black circles in Fig. 1b) were taken that provide wind speed and direction data. In conditions of moderate to high cloud cover, as was seen during parts of the 21 May mission, continuous and complete full wind profiles from a DWL may not be available at all times because of cloud attenuation of the DWL signal. However, it is also possible for the DWL signal to pass through the clouds (optical depths less than 1) to measure winds below the cloud deck during other parts of the mission (as seen on 21 May). In addition to these incomplete data profiles, data are not available during aircraft turns as is normal with airborne DWL missions because of pointing and GPS/INS issues. As seen in online supplemental Fig. S1, 84 profiles (flight legs C, D, E, and start of leg F; black circles with crosses on Fig. 1b) provide data through the vertical column from 150 to $2000 \mathrm{~m}$ MSL while the others (flight legs A and B and end of leg F; open black circles in Fig. 1b) provide data from 2000 to $5000 \mathrm{~m}$ MSL. For the remainder of this paper we will focus on the near-surface (150-2000 m MSL) DAWN profiles.

To obtain the most accurate data possible, postflight processing of the raw DAWN data was undertaken to remove artificial ground speeds, remove the effects of aircraft roll/pitch/yaw, remove frequency jitter, optimize the observations in time and space, and to generate a $75-\mathrm{m}$ vertical data product with a $50 \%$ overlapping of 150-m vertical signal integrations. Comparisons were made between the DAWN wind profile produced every $5-7 \mathrm{~km}$ and the near-instantaneous (within $30 \mathrm{~s}$ ) collocated (within $2.5 \mathrm{~km}$ ) dropsonde. Overall, for the eight dropsondes released during the 21 May missions (some of which were taken before the barrier wind flight transects and are therefore not shown in Fig. 1b), statistical 
comparison between the DAWN wind speed measurements and the more traditional dropsonde observations between the surface and $5 \mathrm{~km}$ show a bias of $-0.05 \mathrm{~m} \mathrm{~s}^{-1}$ and a root-mean-square difference (RMSD) of $2.3 \mathrm{~m} \mathrm{~s}^{-1}$.

For calculating similar statistics-bias, RMSD, and correlation coefficients-between DAWN and dropsonde profiles from 150 to $2000 \mathrm{~m}$ MSL we have interpolated each dataset to the same $10-\mathrm{m}$ vertical grid. Because DAWN data are not available below $2000 \mathrm{~m}$ MSL at locations D1 and D6, we will focus our comparison on locations D2, D3, D4, and D5 where the closest DAWN profile with data below $1000 \mathrm{~m}$ MSL (Fig. 1b, filled black circles) was within 5.9, 2.3, 8.3, and $1.3 \mathrm{~km}$, respectively. To create vertical cross sections, the DAWN profiles have been linearly interpolated to a regular vertical grid with $10-\mathrm{m}$ spacing, and then linearly interpolated onto a regular horizontal grid with $\sim 2.5-\mathrm{km}$ spacing.

\section{b. Satellite observations}

Satellite-derived 10-m wind speed and direction products over non-ice-covered ocean are available from ASCAT MetOp-A and MetOp-B. Gridded data at $12-\mathrm{km}$ grid spacing are available from the four daily satellite passes and the times of the passes listed in this paper correspond to the $65^{\circ} \mathrm{N}$ latitude UTC observation time. All plots of ASCAT winds were generated using satellite data from the Copernicus Marine Service Products (Copernicus Marine Service Products 2016). Hourly satellite cloud imagery from the European Organisation for the Exploitation of Meteorological Satellites (EUMETSAT) MSG satellites and the National Oceanic and Atmospheric Administration (NOAA) polar-orbiting weather satellites was provided by the Icelandic Met Office during the DAWN Polar Winds missions. In particular, we use the hourly cloud product from the SEVERI 10.8- $\mu \mathrm{m}$ (infrared) channel (Icelandic Met Office 2016).

\section{c. WRF simulations}

We use the Advanced Research WRF Model, version 3.7.1 (Skamarock et al. 2008), for simulations over the colored domain shown in Fig. 1a; all simulations used the same domain without nesting. To capture the entire barrier wind event, all WRF simulations started at 0000 UTC 20 May and were spun up for $12 \mathrm{~h}$ in order to correspond to 1200 UTC 20 May, when barrier winds were first noted in the Denmark Strait (see section 3a). The $\sim 70-\mathrm{km}$ European Centre for Medium-Range Weather Forecasts (ECMWF) interim reanalysis (ERA-I) (Dee et al. 2011) performs well in the Arctic (Lindsay et al. 2014; Bromwich et al. 2016), so it is used to provide lateral and lower boundary conditions for all WRF simulations. Previous work has shown WRF has significant cold biases over sea ice that affect upward turbulent heat fluxes if the WRF default sea ice thickness is used (DuVivier and Cassano 2015), so for the simulations presented here we changed the default sea ice thickness in WRF from 3 to $0.5 \mathrm{~m}$. Thinner sea ice is more appropriate along Greenland's east coast (Bourke and Garrett 1987) and also likely better for melt season conditions as would be experienced in May. The following physical parameterizations were used in all WRF simulations: Rapid Radiative Transfer Model for GCMs (RRTMG) longwave and shortwave radiation (Iacono et al. 2008), Kain-Fritsch cumulus (Kain 2004), Morrison microphysics (Morrison et al. 2009) with specified droplet concentrations of $200 \mathrm{~cm}^{-3}$ over land and $50^{-3}$ over ocean and sea ice, revised MM5 surface layer (Jiménez et al. 2012), and Noah land surface model (Niu et al. 2011). Use and evaluation of cumulus parameterizations in the "gray zone" $(5-10 \mathrm{~km})$ is not well documented for the Arctic, but because in the midlatitudes convection is generally not resolved below $4 \mathrm{~km}$ (Prein et al. 2015; Yu and Lee 2010; Weisman et al. 1997) and may still need some parameterization between 1 and $5 \mathrm{~km}$ (Mahoney 2016), we have chosen to use it for all simulations in this study in order to compare identical model configurations. Because the PBL parameterization choice may have a strong impact on near-surface barrier wind conditions, we will present results using both the Mellor-Yamada-Nakanishi-Niino, version 2.5 (MYNN2.5; Nakanishi and Niino 2006) and the University of Washington (UW; Bretherton and Park 2009) schemes, which are also used by the Arctic System Reanalysis (ASR; Bromwich et al. 2016) and Community Earth System Model, version 1 (CESM; Eaton 2011), respectively. These parameterizations, including the modification to the microphysics, have been determined through extensive sensitivity studies to optimize atmospheric performance in the high latitudes for use in RASM (Cassano et al. 2017; DuVivier et al. 2016; Cassano et al. 2011).

We tested four horizontal grid spacings $-5,10,25$, and $50 \mathrm{~km}$ - in otherwise identically configured WRF simulations. The lowest resolution was chosen to be similar to the newest generation reanalyses (ERA-I, $\sim 70 \mathrm{~km}$ ) and regional coupled models such as RASM $(50 \mathrm{~km})$. The highest-resolution simulations are expected to capture the complex Greenland terrain better than the highestresolution regional Arctic System Reanalysis $(15 \mathrm{~km})$, which shows improvement in topographically forced winds when compared to global reanalyses (Bromwich et al. 2016; Moore et al. 2016). The differences in horizontal grid spacing create the largest topographic 
differences along the coast because low grid spacing results in more smoothed terrain-too low over land and too high over the ocean-rather than the ridges that are present in reality. Previous work has shown WRF captures barrier jet features using 40 vertical levels (DuVivier and Cassano 2013), but to understand the importance of vertical resolution on simulating jet structure we compare simulations with 40 and 60 vertical levels that are otherwise identically configured. Oltmanns et al. (2015) explored the impact of horizontal and vertical resolution on simulated downslope (katabatic) flow but they simultaneously varied the grid spacing in both dimensions for their simulations so it is not possible to separate the impact of increasing vertical resolution from the impact of increasing horizontal resolution. The 40 level simulations have 10 levels in the lowest $1 \mathrm{~km}$ with the lowest level at $\sim 12 \mathrm{~m}$ over the ocean; the 60 level simulations have 20 levels in the lowest $1 \mathrm{~km}$ with the lowest level at $\sim 10 \mathrm{~m}$ over the ocean. To increase the vertical resolution, we have targeted additional levels near the surface so that we can better resolve the near-surface jet and boundary layer processes that may be important for driving these near-surface jets. All simulations have a model top of $50 \mathrm{hPa}$. Table 1 lists all WRF simulations discussed in this paper. Each simulation produced instantaneous output every $20 \mathrm{~min}$, and for comparison with observations the closest WRF output time was chosen.

We use spectral nudging in the WRF simulations in order to simulate the barrier wind as realistically as possible for comparison to observations. Spectral nudging is a method of nudging the regional model simulation above specified length scales toward an external dataset, in our cases, the ERA-I, in order to reduce anomalous behavior from the regional simulation (Glisan et al. 2013), and it has been found to most affect sea level pressure (SLP) biases (Berg et al. 2013). For all our simulations, we confine nudging to the temperature and wind fields at large horizontal scales $(>\sim 1000 \mathrm{~km})$ and in the top half of the domain (above $\sim 500 \mathrm{hPa}$ ) in order to constrain only large-scale circulation features while allowing surface features to respond to local processes and develop independently (Berg et al. 2016, 2013; Cassano et al. 2011, 2017; Glisan et al. 2013). The nudging strength is linearly ramped up from 0 at level 20 (30) to $0.0003 \mathrm{~s}^{-1}$ at level $40(60)$, which is consistent with the spectral nudging used in RASM (DuVivier et al. 2016; Roberts et al. 2015; Cassano et al. 2017). When no nudging is applied, WRF quickly drifts from the forcing data and develops large biases in SLP and geopotential height at $500 \mathrm{hPa}$ (Z500), though even with nudging differences exist between
TABLE 1. WRF simulations discussed in this paper. Naming is Wxx-yy-p, where $\mathrm{xx}$ is the horizontal resolution $(\mathrm{km})$, yy is the vertical resolution (No. of levels), and $\mathrm{p}$ is the first letter of the PBL scheme used in the simulation.

\begin{tabular}{lcc}
\hline \hline & 40 vertical levels & 60 vertical levels \\
\hline MYNN 2.5 & W05-40-M & W05-60-M \\
& W10-40-M & \\
& W25-40-M & \\
& W50-40-M & \\
& W05-nonudge & W05-60-U \\
UW & W05-40-U & \\
& W10-40-U & \\
\hline
\end{tabular}

WRF circulation compared to ERA-I (Fig. 2). As a result of the circulation drift, without nudging WRF simulates near-surface wind speeds that are too high and located too close to the ice edge compared to the ASCAT observations at 1800 UTC 21 May (Fig. 2). When nudging is applied, the simulated wind features more closely match the ASCAT observations, circulation biases decrease with height, and around the Z500 level the biases are similar across all horizontal resolutions (not shown). Because the focus of this study is to compare WRF with observations of the particular barrier wind event observed on 21 May 2015, we use nudging for all following simulations comparisons.

To calculate spatial statistics, we interpolate the WRF spatial fields to the ASCAT grid using Earth System Modeling Framework (ESMF) regridding. To calculate vertical statistics between WRF and the dropsonde or DAWN profiles at a point, we use a weighted average of the nearest four points to the latitude and longitude of the observation and then linearly interpolate to a vertical grid with regular 10-m spacing. We calculated the WRF wind speed along the flight legs containing DAWN data using a weighted average of the four nearest points to each of the regularly spaced $2-\mathrm{km}$ positions and then linearly interpolate to a regular $10-\mathrm{m}$ vertical grid. Statistics between WRF, dropsonde, and DAWN profiles are calculated on the regular grid, and in text we focus on the statistics comparing WRF with the dropsondes.

\section{Observations of a barrier wind event}

\section{a. Synoptic situation}

Around 0000 UTC 19 May a cyclone developed off Greenland's southeast coast and stayed relatively stationary (not shown) until 0000 UTC 20 May when it began to move northeastward (Fig. 3a). Strong winds in the Denmark Strait first developed at 1200 UTC 20 May and they persisted as the cyclone moved parallel to the Greenland coast (Figs. 3b-g). By 0000 UTC 22 May the 

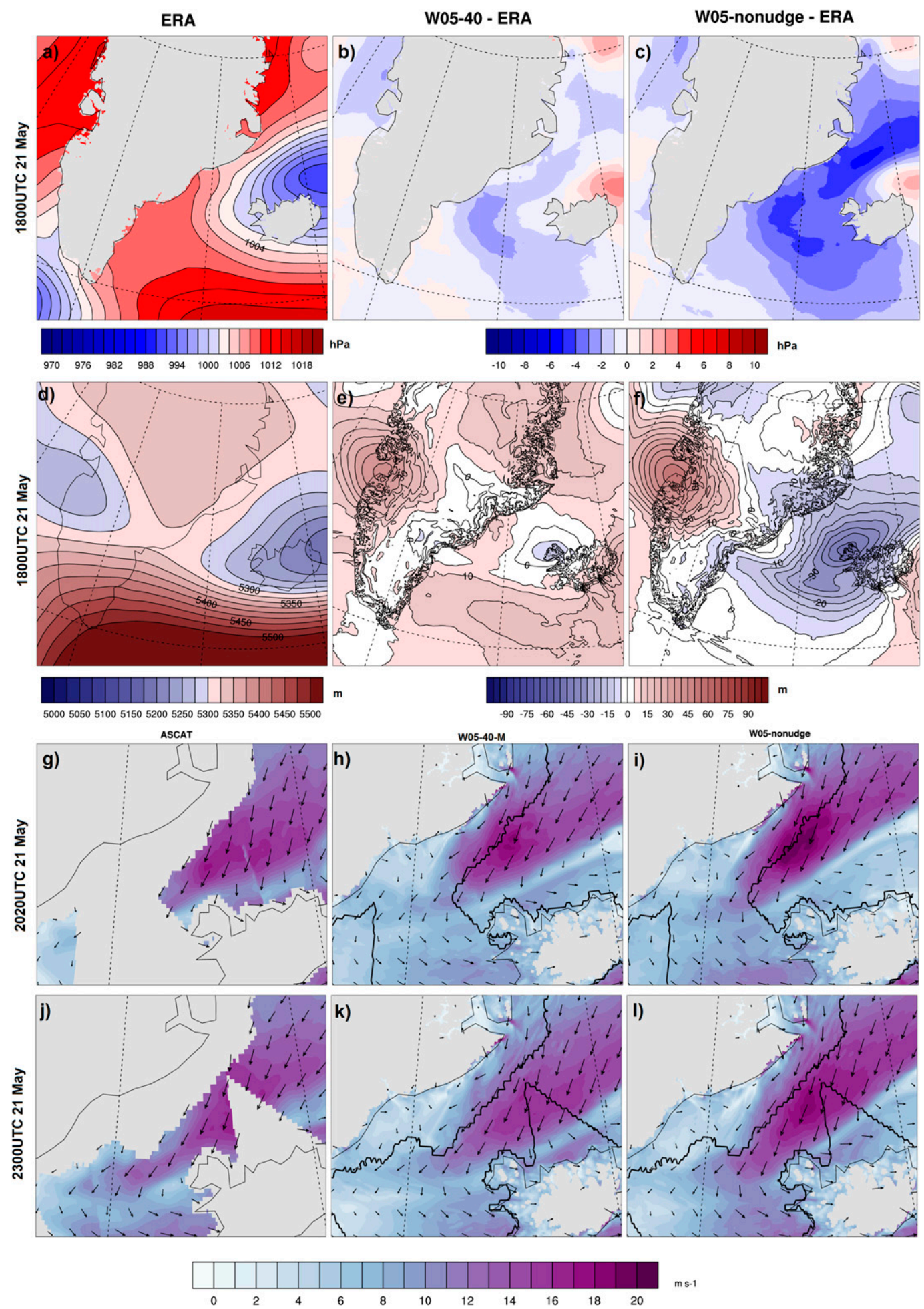

FIG. 2. (a) ERA-I sea level pressure (hPa) at 1800 UTC 21 May 2015, (b) difference in sea level pressure between W05-40-M and ERA-I (hPa), and (c) difference in sea level pressure between W05-nonudge and ERA-I (hPa). (d) ERA-I 500-hPa geopotential height $(\mathrm{m})$ at 1800 UTC 21 May 2015, (e) difference in 500-hPa geopotential height between W05-40-M and ERA-I (m), and (f) difference in 500-hPa geopotential height between W05-nonudge and ERA-I (m). (g),(j) ASCAT 10-m wind field; (h),(k) W05-40-M 10-m wind field; and (i),(l) W05-nonudge 10-m wind field at 2020 and 2300 UTC 21 May, respectively. 

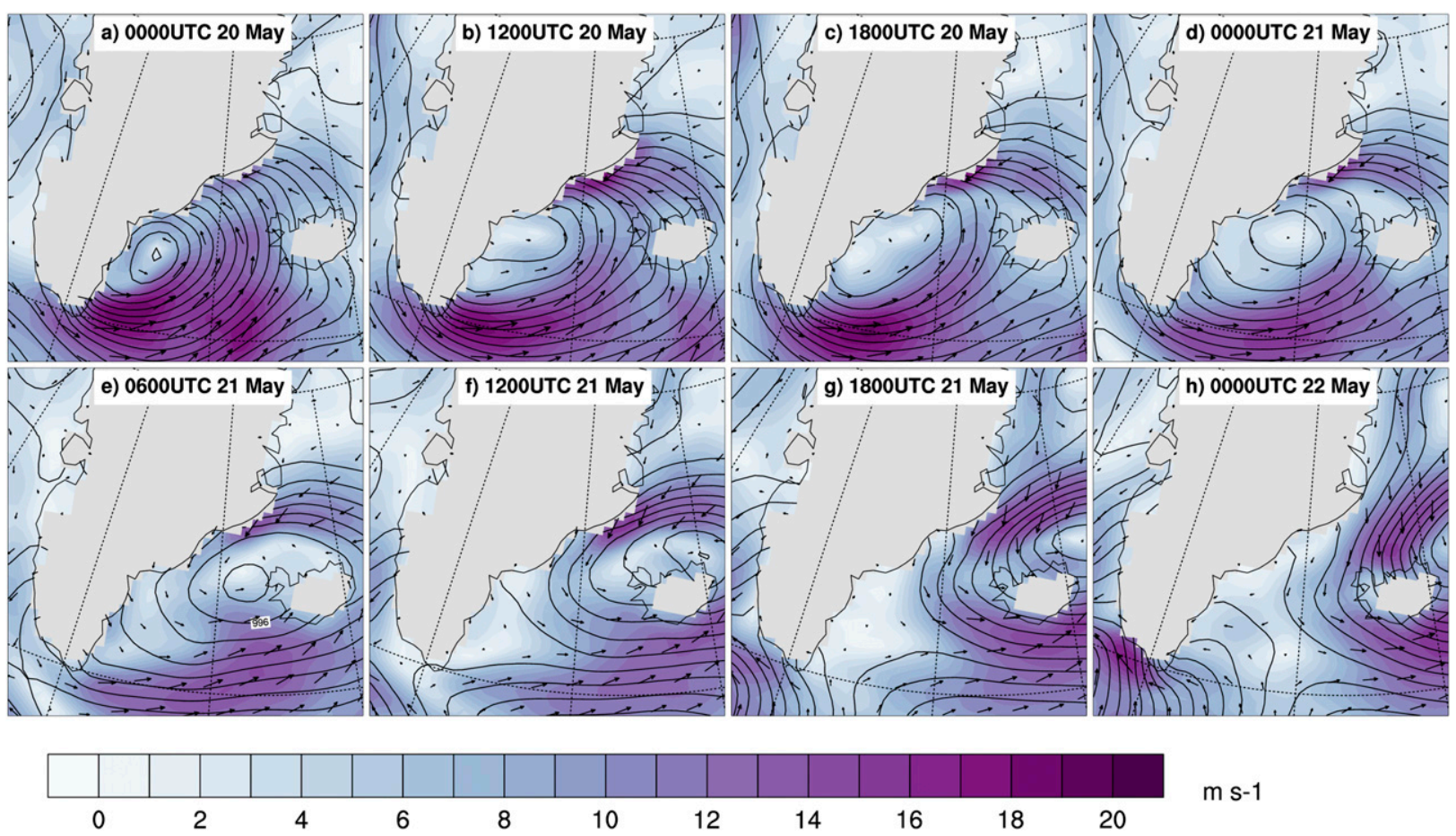

FIG. 3. ERA-I sea level pressure ( $\mathrm{hPa}$, black contours), wind speed ( $\mathrm{m} \mathrm{s}^{-1}$, colored contours), and wind vectors for the barrier wind event at (a) 0000 UTC 20 May, (b) 1200 UTC 20 May, (c) 1800 UTC 20 May, (d) 0000 UTC 21 May, (e) 0600 UTC 21 May, (f) 1200 UTC 21 May, (g) 1800 UTC 21 May, and (h) 0000 UTC 22 May.

cyclone was located east of Iceland and the winds in the Denmark Strait weakened. The aircraft observations were taken between 1900 and 2200 UTC 21 May. Therefore, our analysis period is from 1200 UTC 20 May, when the barrier winds started, until 0000 UTC 22 May when they ended. The analysis will focus primarily on periods that overlap with the aircraft observations and on near-surface conditions.

\section{b. Aircraft observations}

As observed by the dropsondes, the jet structure near the coast differs from the structure farther from the coast. The dropsondes closest to the coast (locations D1, D3, and D5) measure maximum wind speeds of $\sim 21 \mathrm{~m} \mathrm{~s}^{-1}$ (Fig. 4a), while farther from the coast (locations D2, D4, and D6) the maximum speed is stronger at $\sim 25 \mathrm{~m} \mathrm{~s}^{-1}$ (Fig. 4e). Near the coast the jet peaks at $\sim 300 \mathrm{~m}$ MSL (D3 and D5), while far from the coast the jet is much broader and has relatively uniform speed from 300 to $1100 \mathrm{~m}$ MSL (D2 and D4). All dropsondes show primarily northeasterly winds (Figs. 4b,e), though at D3 and D5 the winds aloft become northerly. Near the coast, the dropsondes D1, D3, and D5 all have temperature inversions at the same height as their respective jet maxima (Fig. 4c), far from the coast the temperature inversions do not correspond to a similar wind speed maximum (Fig. 4f). For comparisons with WRF simulations we will focus on dropsondes locations D2, D3, D4, and D5 since they clearly capture the barrier flow and show similar jet structure near and far from the coast.

DAWN wind profiles at locations D2-5 (L2-5 in Fig. 4) show a barrier wind jet very similar to that observed by the dropsondes: narrow and peaked near the coast and broader farther from the coast. As seen in Table 2, DAWN has RMSD $<2 \mathrm{~m} \mathrm{~s}^{-1}$ at all four locations with a positive bias at D2 $\left(1.14 \mathrm{~m} \mathrm{~s}^{-1}\right)$ and small negative biases at dropsondes D3 $\left(-0.03 \mathrm{~m} \mathrm{~s}^{-1}\right), \mathrm{D} 4$ $\left(-1.5 \mathrm{~m} \mathrm{~s}^{-1}\right)$, and D5 $\left(-1.13 \mathrm{~m} \mathrm{~s}^{-1}\right)$. At all four locations, the lidar observations have similar structure to the dropsondes and are highly correlated in both wind speed (Table 2: 0.92, 0.84, 0.95, and 0.92, respectively) and direction (supplemental Table S1: 0.87, 0.98, 0.73, and 0.99 , respectively).

Frequent near-surface vertical wind profiles measured by DAWN along flight legs C, D, E, and F (Fig. 1b, circles with crosses; upward-pointing triangles in Fig. 5) provide more numerous data profiles through the barrier jet than the more infrequently spaced dropsondes and provide a broad view of the jet structure. While the DAWN data are unfortunately not available in the central core of the jet due to cloud 

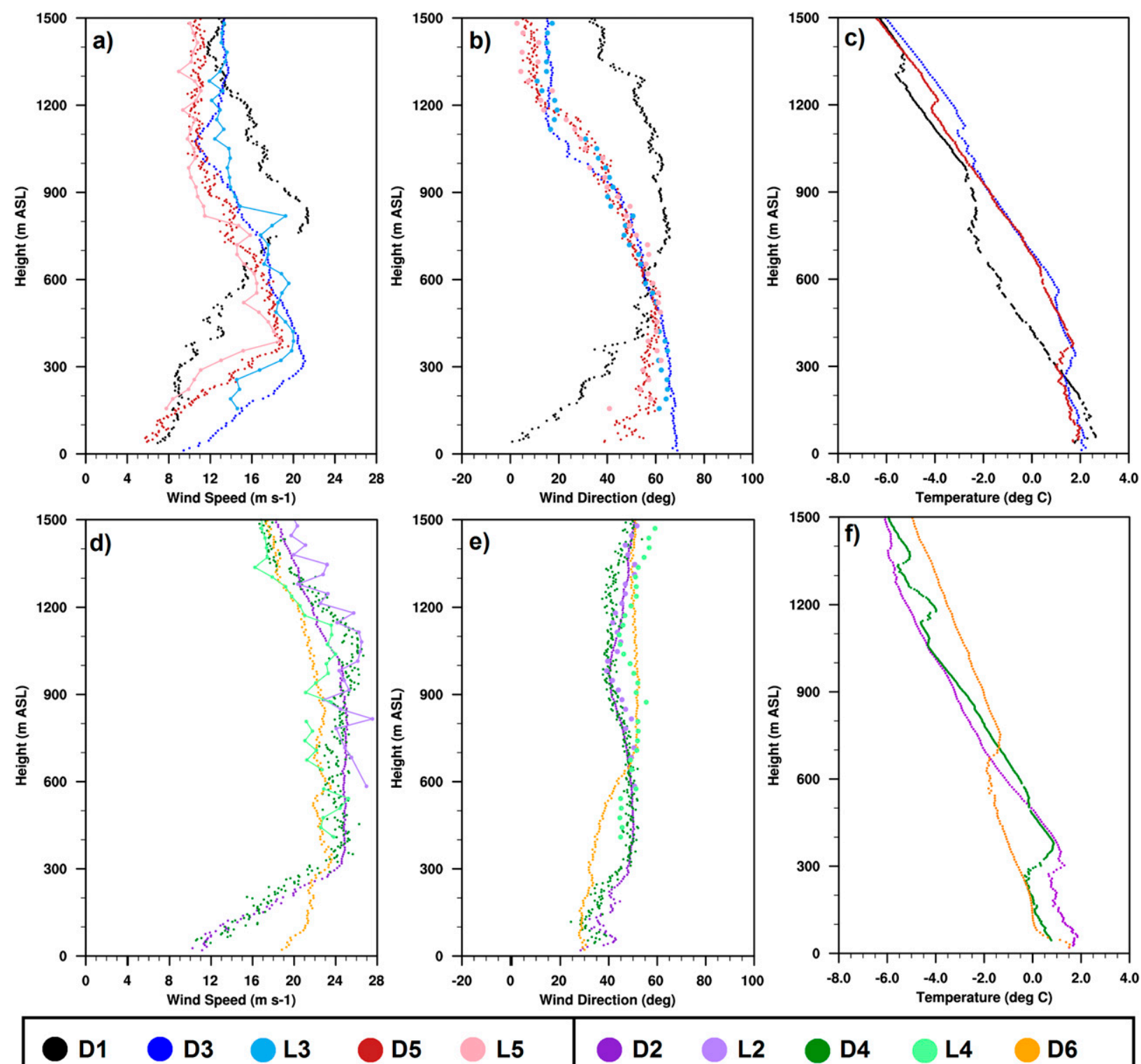

D5

L5

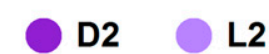

L2 D4

L4

D6

FIG. 4. Dropsonde profiles of (a),(d) wind speed $\left(\mathrm{m} \mathrm{s}^{-1}\right)$; (b),(e) wind direction $\left({ }^{\circ}\right)$; and (c),(f) temperature $\left({ }^{\circ} \mathrm{C}\right)$. (a)-(c) Dropsonde locations D1 (black; 1946 UTC), D3 (blue; 2030 UTC), D5 (red; 2059 UTC) are shown that are located nearer the Greenland coast, while (d)-(f) dropsonde locations D2 (purple; 2011 UTC), D4 (green; 2044 UTC), and D6 (orange; 2119 UTC) are shown that are located farther from the Greenland coast as seen on the map in Fig. 1b. (a),(b),(d),(e) DAWN lidar wind speed and direction profiles below $1500 \mathrm{~m}$ MSL at locations nearest D2 (light purple), D3 (light blue), D4 (light green), and D5 (pink) are shown with the corresponding dropsondes.

cover, we are still able to glean important information about the jet structure. Figure 5 indicates that the jet occurs below $2 \mathrm{~km}$ MSL and is at least $150 \mathrm{~km}$ wide. Additionally, the DAWN observations indicate smallscale wind features $(\sim 10 \mathrm{~km})$ within the main barrier jet (e.g., Fig. $5 \mathrm{~b}, \sim 400 \mathrm{~m}$ MSL and $\sim 35 \mathrm{~km}$; Fig. $5 \mathrm{~d}$, $\sim 1600 \mathrm{~m}$ MSL and $\sim 55 \mathrm{~km}$ ). These flight legs show that the barrier jet has a narrow peak below $800 \mathrm{~m}$ MSL near the coast and that it broadens to around $2000 \mathrm{~m}$
MSL with distance away from the coast and the wind speeds increase as well.

\section{WRF simulations}

In the following section, we compare the WRF simulations with available observations. When analyzing the impact of particular factors (horizontal resolution, vertical resolution, PBL scheme, etc.), we will compare 


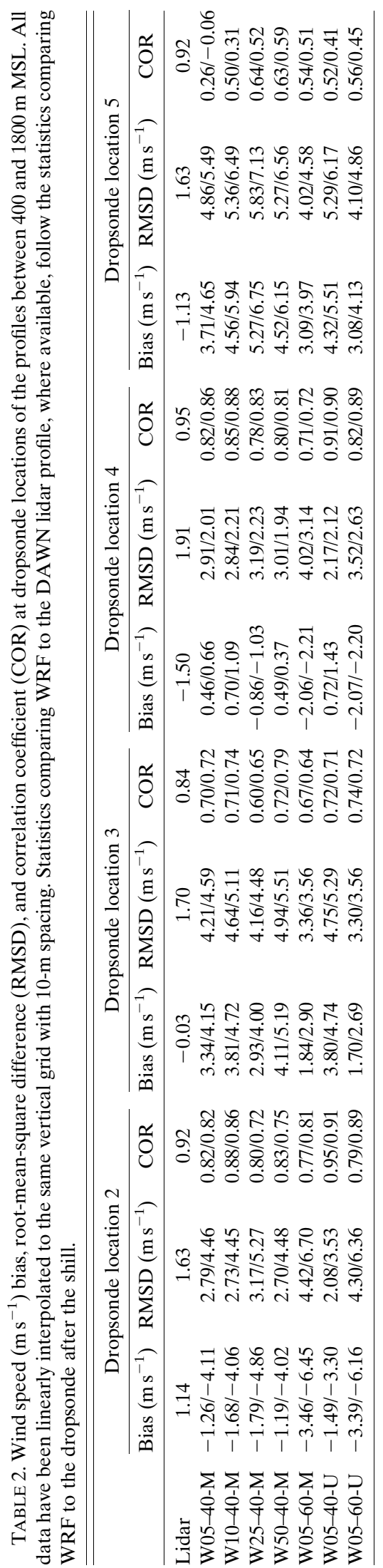

only simulations configured identically except for the given aspect. Therefore, to understand the impact of horizontal grid spacing, we will compare only simulations with 40 vertical levels and the MYNN2.5 PBL scheme; to understand the impact of vertical resolution, we will compare only 5-km horizontal grid spacing with the same PBL scheme; and to understand the importance of the PBL scheme, we will compare 5-km horizontal grid spacing with the same number of vertical levels. The full list of WRF simulations we discuss is provided in Table 1.

\section{a. ASCAT surface wind comparison}

The horizontal grid spacing of WRF has a strong impact on the representation of barrier jets in the 10-m wind field. At 1340 UTC 21 May, the jet is located close to the coast and over sea ice (Fig. 6a). While ASCAT does not capture the jet core due to the sea ice coverage, it does capture the cyclone center and jet inflow. Adjacent to the coast, and over the sea ice, there is a distinct jet extending from the Greenland terrain in the high-resolution WRF simulations (Figs. 6b,c), but in the lower-resolution simulations the wind speeds in this jet decrease (Figs. 6d,e). Compared to ASCAT, differences in the10-m wind speed north of Iceland in the jet inflow region show that $5-\mathrm{km}$ WRF has biases around $-5 \mathrm{~m} \mathrm{~s}^{-1}$ while the $50-\mathrm{km}$ WRF has negative biases in excess of $-10 \mathrm{~m} \mathrm{~s}^{-1}$ and over a larger footprint (Table 3; Figs. 6i-1). This negative bias is the result of both the jet being too weak and the jet edge being located too far north. At 2020 UTC 21 May the barrier jet has moved southward due to the cyclone continuing to track northeastward, and the jet maxima is now visible over open water in the Denmark Strait (Fig. 7a). At this later time of the model run, the simulations with $5-\mathrm{km}$ grid spacing do a relatively good job of capturing the shape and speeds of the jet, though the maximum speeds still exceed those observed by ASCAT, but the feature appears to be misplaced and is closer to the ice edge than observed (Figs. 7a,b,f-h). The WRF simulations with larger grid spacing also place the barrier jet too far north along the ice edge, but with larger grid spacing the jet also has too weak of maximum wind speeds and differently shaped from observations (Figs. 7b-e). As a result of the misplaced barrier jet feature, WRF has a high wind speed bias along the ice edge and a low speed bias farther south (Figs. 7i-o), though the biases tend to be smallest for the simulations with $5-\mathrm{km}$ grid spacing because of the feature's better spatial shape and more similar wind speeds to observations. For both ASCAT passes, on average, the bias and RMSD decrease by 0.19 and $0.14 \mathrm{~m} \mathrm{~s}^{-1}$, respectively, and the spatial correlation increases by 0.05 with increasing horizontal resolution (Table 3). 

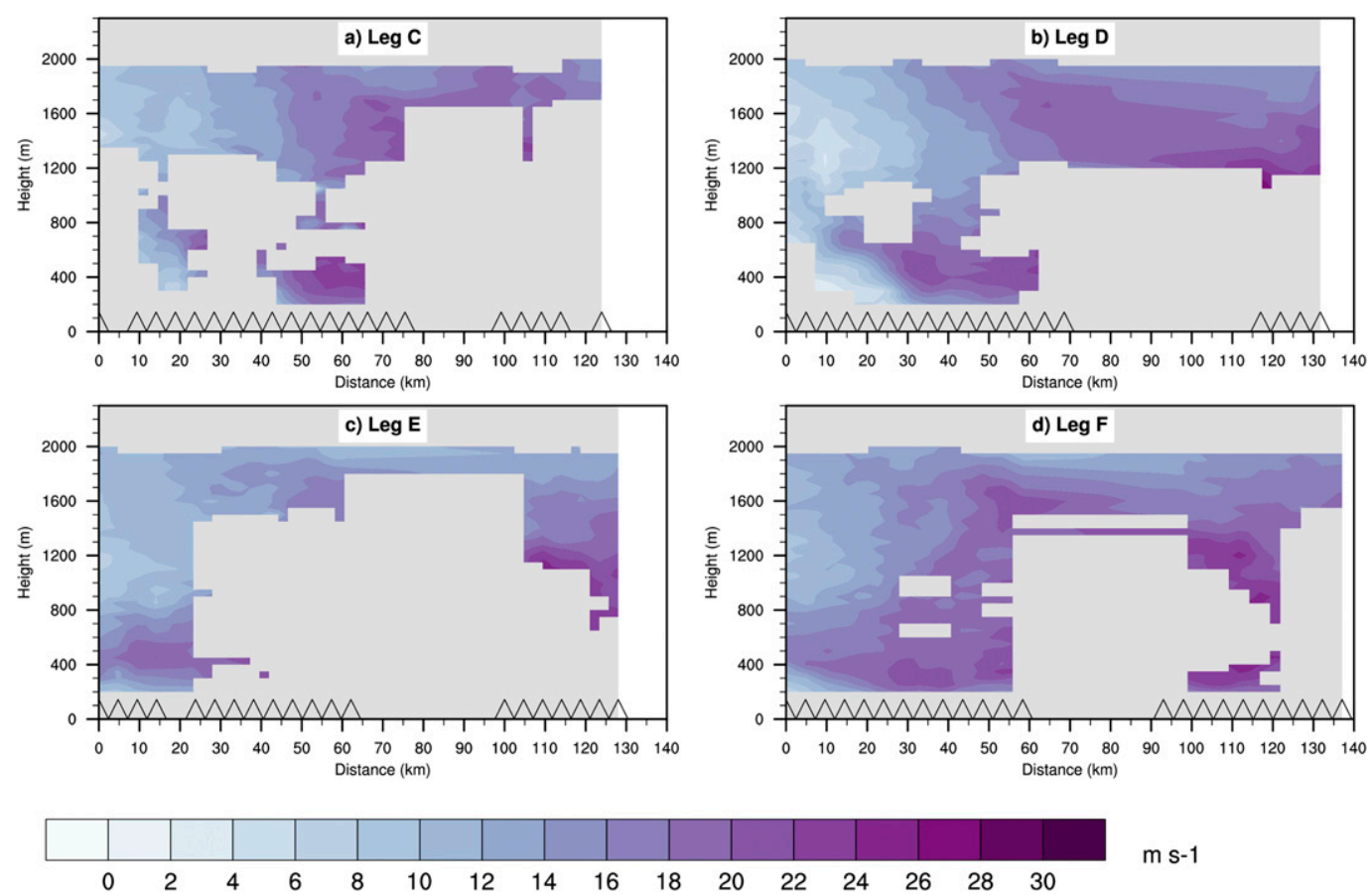

FIG. 5. Vertical cross sections of total wind speed $\left(\mathrm{m} \mathrm{s}^{-1}\right)$ from the DAWN lidar along flight legs (a) C (20102023 UTC), (b) D (2026-2040 UTC), (c) E (2042-2056 UTC), and (d) F (2059-2114 UTC). The 0-km horizontal distance for each flight leg corresponds to the location nearest the coast. Black triangles along the $x$ axis correspond to locations of DAWN profiles shown in Fig. 1b with black circles with crosses only. All cross sections are plotted on a horizontal axis of $140 \mathrm{~km}$ and height of $2.3 \mathrm{~km}$ so that features can be directly compared.

Increasing the vertical resolution in the $5-\mathrm{km}$ simulations (W05-40-M vs W05-60-M or W05-40-U vs W05-60-U) leads to slightly lower RMSD values $\left(0.11 \mathrm{~m} \mathrm{~s}^{-1}\right)$ and higher correlations $(0.02)$ on average for both PBLs and both times (Table 3). Although the spatial wind speed bias fields are relatively similar at both 1340 and 2020 UTC 21 May, small improvements can be seen with increased vertical resolution (Figs. $5 \mathrm{i}$ vs $5 \mathrm{~m}, 5 \mathrm{n}$ vs $5 \mathrm{o}, 6 \mathrm{i}$ vs $6 \mathrm{~m}$, and $6 \mathrm{n}$ vs $6 \mathrm{o}$ ). Because of the importance of high terrain for forcing the coastal jets in the Denmark Strait, it is not surprising that higher spatial and vertical grid spacing can better represent the steep coastal terrain necessary to simulate strong, realistic jets.

The 10-m wind fields simulated by the MYNN2.5 and UW PBL schemes do not differ significantly in overall structure and have similar maximum wind speeds in the barrier jet. The UW simulations, however, have more variable jet cores with localized pockets of low speed winds that occur near the ice edge (Figs. 6 and 7). These pockets of lower wind speeds are not seen in the MYNN2.5 simulations or the ASCAT observations, but the UW turbulent flux field structure mirrors the wind speeds and has areas of low fluxes within the generally high fluxes collocated with the barrier jet (not shown).

\section{b. WRF-dropsonde vertical profile comparison}

Having high horizontal resolution is important for capturing the vertical jet structure near the coast. At location D3 and D5, all horizontal resolutions of WRF have a positive wind speed bias compared to the dropsondes, but the lower horizontal resolutions result in a smoother jet structure and generally larger wind speed RMSD (Table 2; Figs. 8a,d). At location D5, only W0540-M (red) has a clear jet, but it is narrower and about $150 \mathrm{~m}$ lower than the observed jet. All WRF resolutions have northeasterly winds at locations D3 and D5 (Figs. 8b,e), and 5-km simulations have lower RMSD by $11.7^{\circ}$, on average, for wind direction compared to $50 \mathrm{~km}$ (supplemental Table S1). However, none of the simulations capture the shift to northerly wind direction around $1200 \mathrm{~m}$ MSL, which is reflected by increasingly poor direction correlation with decreasing resolution (supplemental Table S1). Away from the coast, at locations D2 and $\mathrm{D} 4$, none of the horizontal resolutions captures the broadened jet (Figs. 9a,d), which is reflected by the similar RMSD and correlation at both locations D2 and D4 

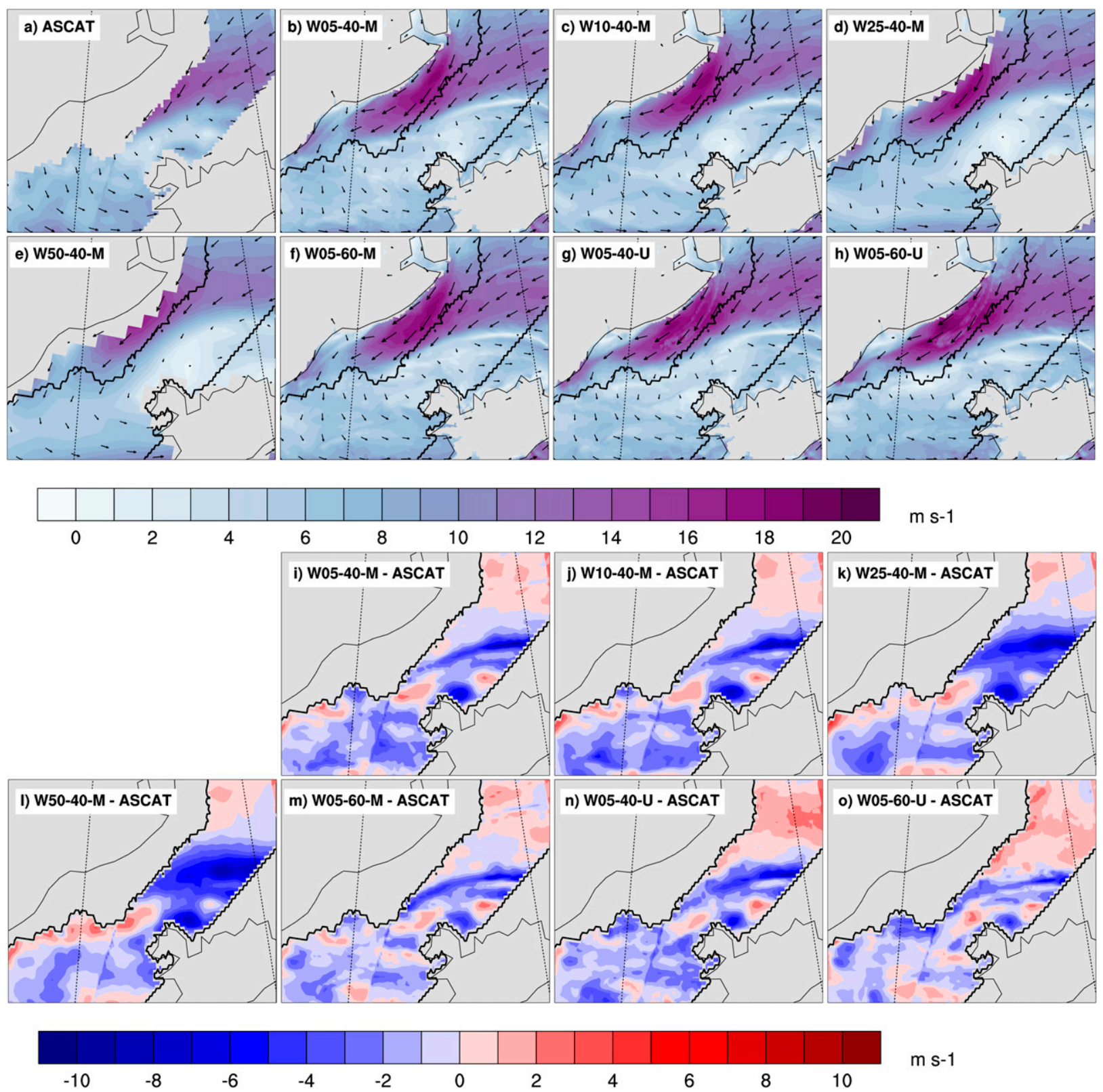

FIG. 6. The 10-m wind speed $\left(\mathrm{m} \mathrm{s}^{-1}\right)$ at 1340 UTC 21 May for (a) ASCAT satellite, (b) W05-40-M, (c) W10-40-M, (d) W25-40-M, (e) W50-40-M, (f) W05-60-M, (g) W05-40-U, and (h) W05-60-U. Differences between wind speed between ASCAT and (i) W05-40-M, (j) W10-40-M, (k) W25-40-M, (l) W50-40-M, (m) W05-60-M, (n) W05-40-U, and (o) W05-60-U. Black lines on the WRF plots show the extent of the ASCAT observations and land points in WRF that have been masked.

for each resolution (Table 2). Away from the coast all resolutions successfully capture the northeasterly wind direction over the profile depth (Figs. 9b,e).

While increasing vertical resolution [W05-40-M (red) vs W05-60-M (pink) and W05-40-U (dark blue) vs W05-60-U (light blue) in Figs. 8 and 9 and Table 2] has little impact on the wind direction either near or far from the coast (Figs. 8b,e, and 9b,e), it does impact the jet wind speed structure. Near the coast, increasing vertical resolution results in weaker jets closer to observed wind speeds, but the shape and height of the simulated jets is relatively unchanged (Figs. 8a,d). As a result of the decreased speeds in the simulations with 60 vertical levels, locations D3 and D5 have lower RMSD by $1.1 \mathrm{~m} \mathrm{~s}^{-1}$ when compared to their 40 level counterparts for both PBL schemes (Table 2). At locations D2 and D4, far from the coast, increasing vertical resolutions also leads to a more peaked jet with slower wind speeds (Figs. 9a,d). 
TABLE 3. Wind speed statistics comparing WRF to ASCAT passes. Statistics are calculated for the ASCAT passes at 1340 UTC 21 May (shown in Fig. 5) and 2020 UTC 21 May (shown in Fig. 6). All statistics are calculated over open ocean points in the region from $64^{\circ}-71^{\circ} \mathrm{N}$ to $15^{\circ}-35^{\circ} \mathrm{W}$ (area shown in Fig. 5).

\begin{tabular}{|c|c|c|c|c|c|c|}
\hline & \multicolumn{3}{|c|}{1340 UTC } & \multicolumn{3}{|c|}{2020 UTC } \\
\hline & $\operatorname{Bias}\left(\mathrm{m} \mathrm{s}^{-1}\right)$ & $\operatorname{RMSD}\left(\mathrm{m} \mathrm{s}^{-1}\right)$ & COR & $\operatorname{Bias}\left(\mathrm{m} \mathrm{s}^{-1}\right)$ & $\operatorname{RMSD}\left(\mathrm{m} \mathrm{s}^{-1}\right)$ & COR \\
\hline W05-40-M & -0.24 & 1.62 & 0.80 & -0.28 & 1.81 & 0.81 \\
\hline W10-40-M & -0.27 & 1.64 & 0.79 & -0.38 & 1.88 & 0.80 \\
\hline W25-40-M & -0.33 & 1.73 & 0.77 & -0.47 & 1.95 & 0.78 \\
\hline W50-40-M & -0.34 & 1.76 & 0.75 & -0.55 & 1.98 & 0.77 \\
\hline W05-60-M & -0.18 & 1.57 & 0.80 & -0.22 & 1.73 & 0.82 \\
\hline W05-40-U & 0.07 & 1.68 & 0.79 & -0.08 & 2.0 & 0.76 \\
\hline W05-60-U & 0.18 & 1.55 & 0.82 & -0.03 & 1.84 & 0.81 \\
\hline
\end{tabular}

However, because the observed jet is broader far from the coast, the RMSD for both locations and PBL schemes increases by $1.6 \mathrm{~m} \mathrm{~s}^{-1}$ and correlation decreases by 0.1 for 60 levels compared to 40 levels (Table 2).

Near the coast, the wind jets from the UW PBL simulations have a larger positive speed bias and RMSD compared to MYNN2.5 [W05-40-M (red) vs W05-40-U (dark blue) and W05-60-M (pink) vs W05-60-U (light blue) in Figs. 8 and 9 and Table 2]. While the jet shapes are similar at locations D3, at D5 the UW produces a smoother wind profile without the jet peak around $150 \mathrm{~m}$ MSL found in the MYNN2.5 simulations. Far from the coast, the difference between the MYNN2.5 and UW PBL schemes is less apparent. The jet structure is similar for each PBL scheme, especially the two simulations with 60 vertical levels (Figs. 9a,d). However, on average at locations D2 and D4 the RMSD is $0.31 \mathrm{~m} \mathrm{~s}^{-1}$ lower while the correlation is higher by 0.06 for UW than MYNN2.5 with 60 vertical levels (Table 2).

Both near and away from the coast, WRF captures the near-surface temperature structure with relatively small biases and high correlations (supplemental Table S2). Inversions around $300 \mathrm{~m}$ are present in all observed profiles (Figs. 8c,f and 9c,f), but to capture these inversions aloft WRF requires both high horizontal and vertical resolution. At location D3, W05-40-M (red) has a slight indication of an inversion aloft while all other horizontal resolutions miss the inversion, but W05-60-M (pink) results in a defined, though too strong, inversion at about the right height (Fig. 8c). At D5, W05-40-M (red) is again the only horizontal resolution to capture the inversion aloft, though it is stronger and lower than the observed inversion. At D5 W05-60-M (pink) also has a strong inversion aloft, but nearer the surface than for W05-40-M (Fig. 8f). Additionally, near the coast neither W05-40-U nor W05-60-U (dark blue and light blue, respectively) capture the inversion as well as the corresponding MYNN2.5 schemes (red and pink, respectively). Far from the coast, at locations D2 and D4, all horizontal resolutions have weak inversions aloft, but in these cases increasing vertical resolution (W05-60-M, pink) results in a slightly more defined inversion that is still too weak and too high compared to observations (Figs. 9c,f). However, at both D2 and D4, the UW simulations [W05-40-U (dark blue) and W0560-U (light blue)] better capture the inversion compared to the corresponding MYNN2.5 simulations [W05-40-M (red) and W05-60-M (pink)]. Thus, both high horizontal and vertical resolution is necessary to simulate the observed inversions, which in turn may have an important influence on wind jet height and strength. Still, increasing vertical resolution may not result in accurate height of the temperature inversion.

\section{c. WRF-DAWN vertical profile comparison}

For comparisons between DAWN wind profiles with WRF simulations we will focus on flight legs D and F because they have the largest number of DAWN profiles with data throughout the column (Fig. 5). (Corresponding cross-sectional comparisons between DAWN and WRF for flight legs $\mathrm{C}$ and $\mathrm{E}$ are shown in supplemental Fig. S2.) We will discuss only the 5-km WRF simulations because they have high enough horizontal resolution to capture the features observed while the lower-resolution simulations will undersample the flight leg. Over flight legs D and F, the DAWN observed jet is relatively thin and bounded below $800 \mathrm{~m}$ MSL, but with distance from the coast the jet broadens and maximum wind speeds increase (Figs. 10a and 10f). In general, the WRF simulated barrier jets are smoother than the DWL profiles because WRF has an effective resolution of $7 \Delta x$ (Skamarock 2004), so the 5-km simulations could only capture features $35 \mathrm{~km}$ or greater in size while some features observed by the lidar are $\sim 5-10 \mathrm{~km}$ in size.

In all cases, increased vertical resolution improves the simulation of the barrier jet. Along both legs D and F, simulations with 40 vertical levels W05-40-M (Figs. 10b and 10g) and W05-40-U (Figs. 10d and 10f) result in jet cores that are too broad, too strong, and smoother than observations. For leg D, the 60 level simulations 

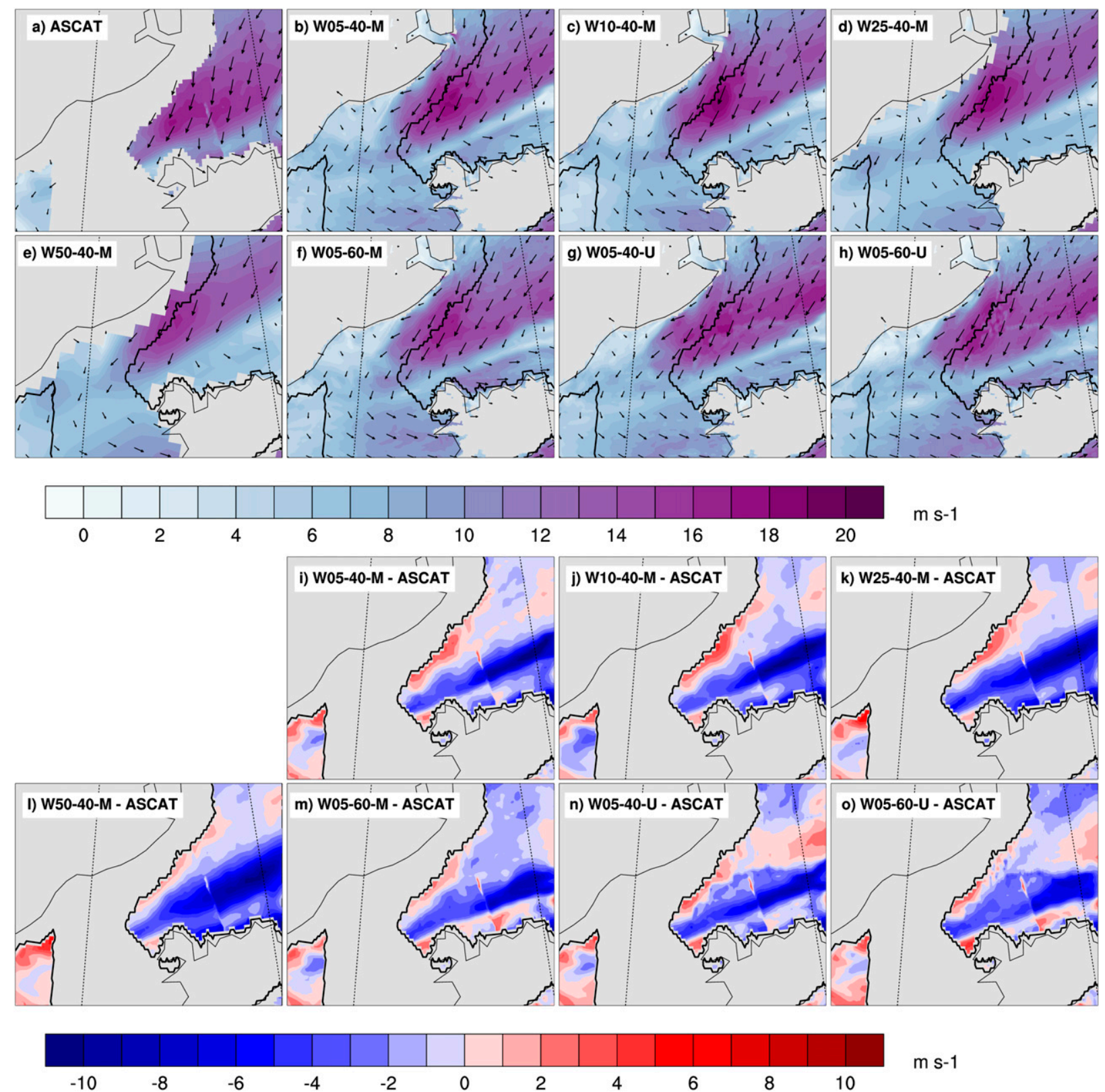

FIG. 7. The 10-m wind speed $\left(\mathrm{m} \mathrm{s}^{-1}\right.$ ) at 2020 UTC 21 May for (a) ASCAT satellite, (b) W05-40-M, (c) W10-40-M, (d) W25-40-M, (e) W50-40-M, (f) W05-60-M, (g) W05-40-U, and (h) W05-60-U. Differences between wind speed between ASCAT and (i) W05-40-M, (j) W10-40-M, (k) W25-40-M, (l) W50-40-M, (m) W05-60-M, (n) W05-40-U, and (o) W05-60-U. Black lines on the WRF plots show the extent of the ASCAT observations and land points in WRF that have been masked.

W05-60-M (Fig. 10c) and W05-60-U (Fig. 10e) better capture the shape and speeds of the jet peak near the coast, though the wind speeds above $1200 \mathrm{~m}$ MSL farther from the coast $(\sim 70 \mathrm{~km})$ are too low in these simulations. Along leg F, the 60 level simulations W05-60-M (Fig. 10h) and W05-60-U (Fig. 10j) have narrower jets with weaker winds compared to the 40 vertical level simulations. However, neither vertical resolution correctly captures the broadening of the jet by $70 \mathrm{~km}$ from the coast, as seen in the observations. Additionally, even the higher vertical resolution is insufficient to capture the sharp wind speed gradients observed.

For both flight legs D and F, the UW PBL scheme with 60 vertical levels performs slightly better than the corresponding MYNN2.5 scheme, particularly near the coast. For leg D, W05-60-U (Fig. 10e) better captures the downward movement of the jet near the coast $(\sim 10$ $40 \mathrm{~km})$ as well as lower wind speeds aloft at this location 

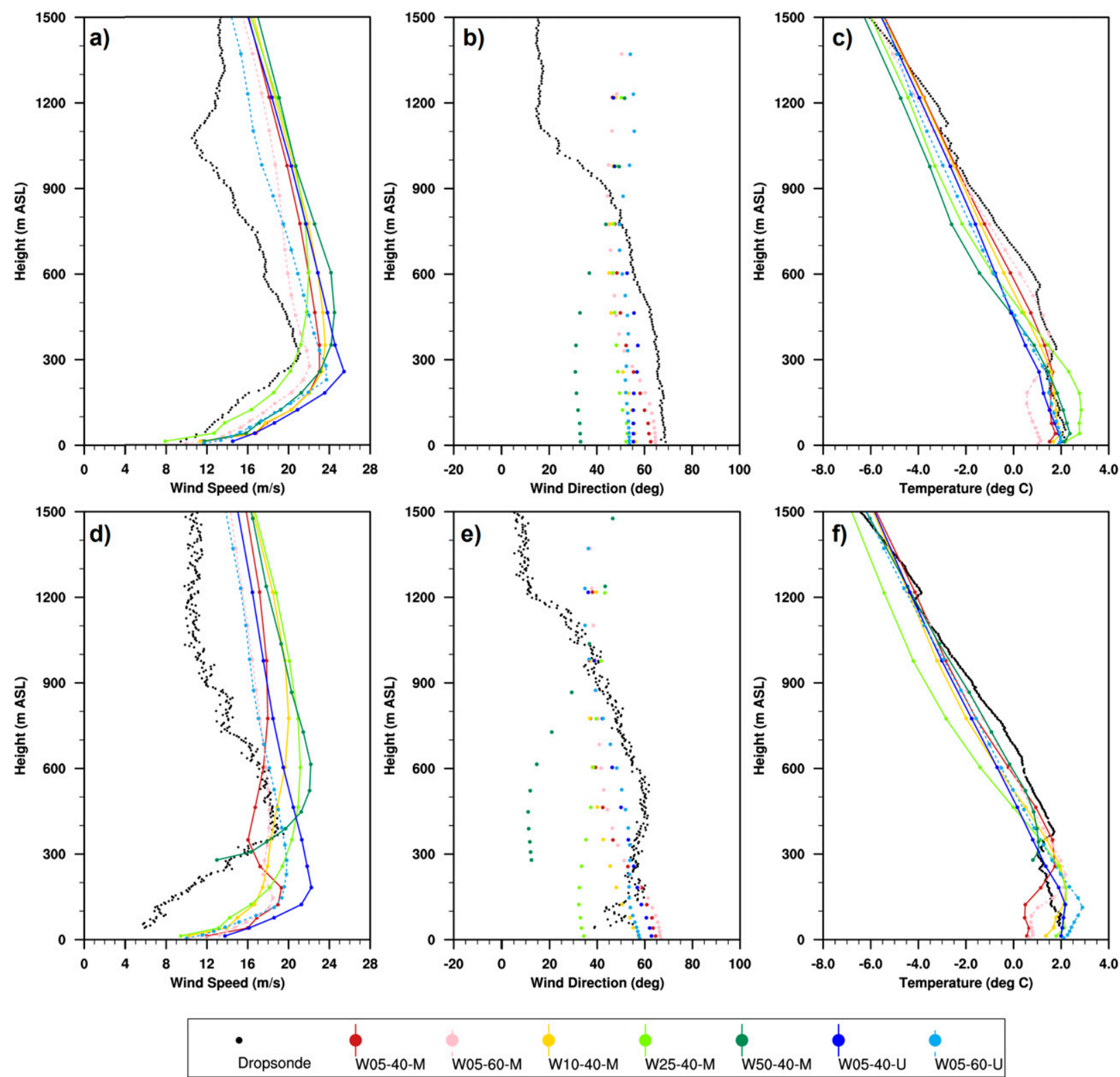

FIG. 8. Near-coast dropsonde, lidar, and WRF (a),(d) wind speed $\left(\mathrm{m} \mathrm{s}^{-1}\right)$; (b),(e) wind direction $\left({ }^{\circ}\right)$; and (c),(f) temperature $\left({ }^{\circ} \mathrm{C}\right)$ in the lowest $1500 \mathrm{~m}$. Profiles at location D3 (2030 UTC) are shown in (a)-(c) while profiles at location D5 (2059 UTC) are shown in (d)-(f). WRF profiles are a weighted average of the nearest four surrounding points.

as compared to W05-60-M (Fig. 10c). For leg F, W0560-U (Fig. 10j) scheme better captures the narrow jet peak around $300 \mathrm{~m}$ MSL as compared to W05-60-M (Fig. 10h). However, while the high speed bias is improved, UW still has too fast wind speeds and does not capture the jet broadening with distance from the coast or the sharp wind speed gradients.

\section{d. Cloud comparison}

In contrast to winter months when turbulent fluxes drive surface buoyancy loss (DuVivier et al. 2016), in
May the surface energy budget is dominated by radiative fluxes. Resulting from the long daylight hours at this high latitude, the incoming shortwave radiation is particularly important this time of year. The amount and location of incoming shortwave radiation has implications for physical processes influencing melting sea ice, upper-ocean heating, thermocline structure, ocean stability, and biological processes, thus differences in simulated cloudiness in WRF could have far ranging implications. At 1800 UTC 21 May, satellite observations show denser cloud cover over the Iceland coast as 

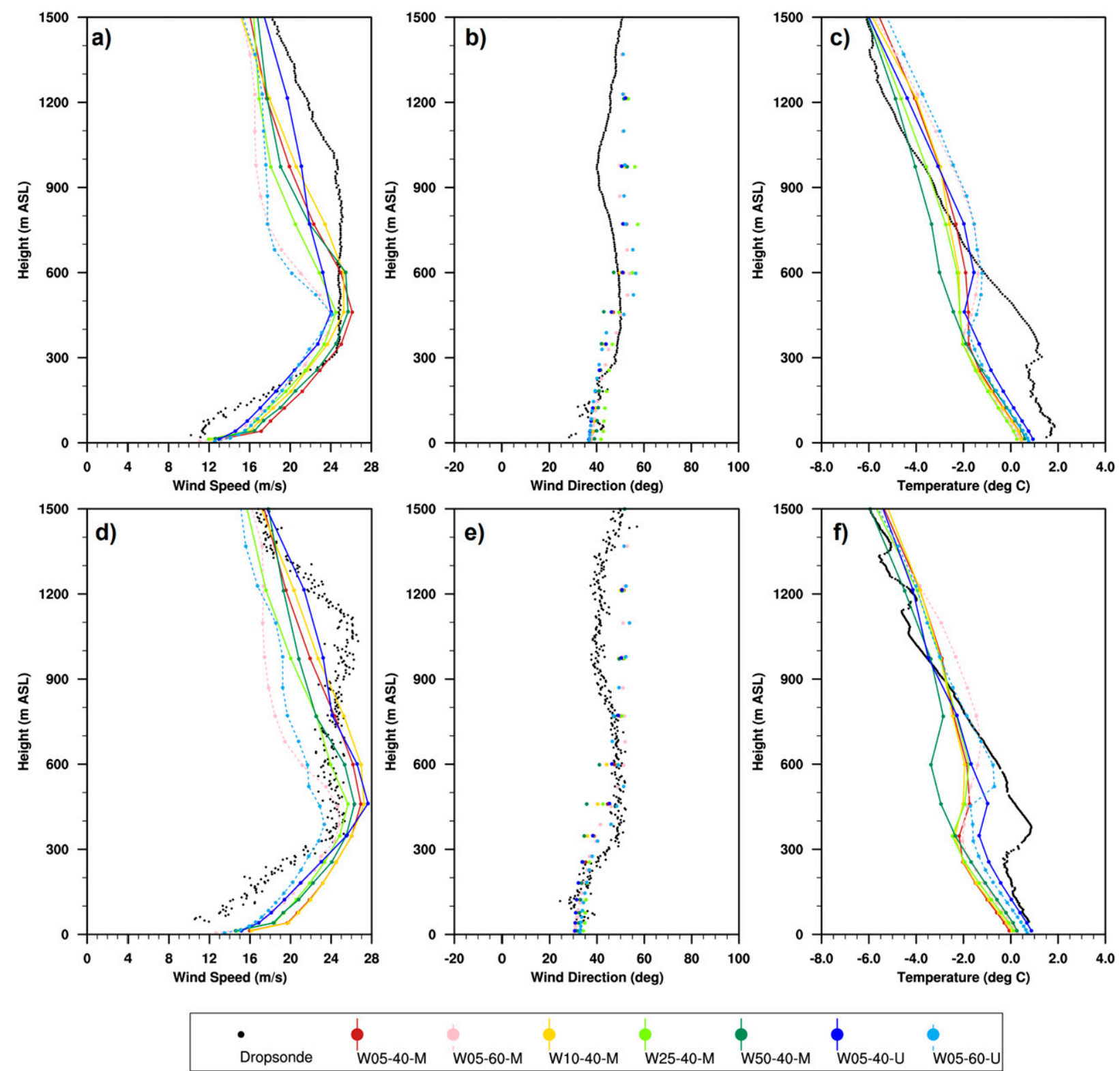

FIG. 9. Far-coast dropsonde and WRF (a),(d) wind speed $\left(\mathrm{m} \mathrm{s}^{-1}\right)$; (b),(e) wind direction $\left({ }^{\circ}\right)$; and (c),(f) temperature $\left({ }^{\circ} \mathrm{C}\right)$ in the lowest $1500 \mathrm{~m}$. Profiles at location D2 (2011 UTC) are shown in (a)-(c) while profiles at location D4 (2044 UTC) are shown in (d)-(f). WRF profiles are a weighted average of the nearest four surrounding points.

compared to the Greenland coast on the western side of the Denmark Strait (Fig. 11a). These images agree well with conditions observed during the flight of a thick, low cloudbank in the Denmark Strait that prevented complete DAWN profile measurements in some instances. There are relatively clear conditions in the south of the Denmark Strait as well as immediately south and east of Iceland.

To evaluate the simulated clouds, we will compare the upward shortwave radiation at the top of the atmosphere in WRF with the satellite image discussed in the previous paragraph. At 1800 UTC 21 May, all WRF simulations (Figs. 11b-h) have too much cloud cover in the Denmark Strait and most have too much cloud south of Iceland as well. All simulations also have a narrow band of clear sky north of Iceland that is not shown in the observations. From 1800 to 2300 UTC 21 May, WRF did simulate gradual clearing of the Greenland coast and increased cloudiness toward the Iceland coast (not shown) that is consistent with satellite- and aircraftbased observations. Though the gross features of the cloud field (cloud band location, locations with thicker 

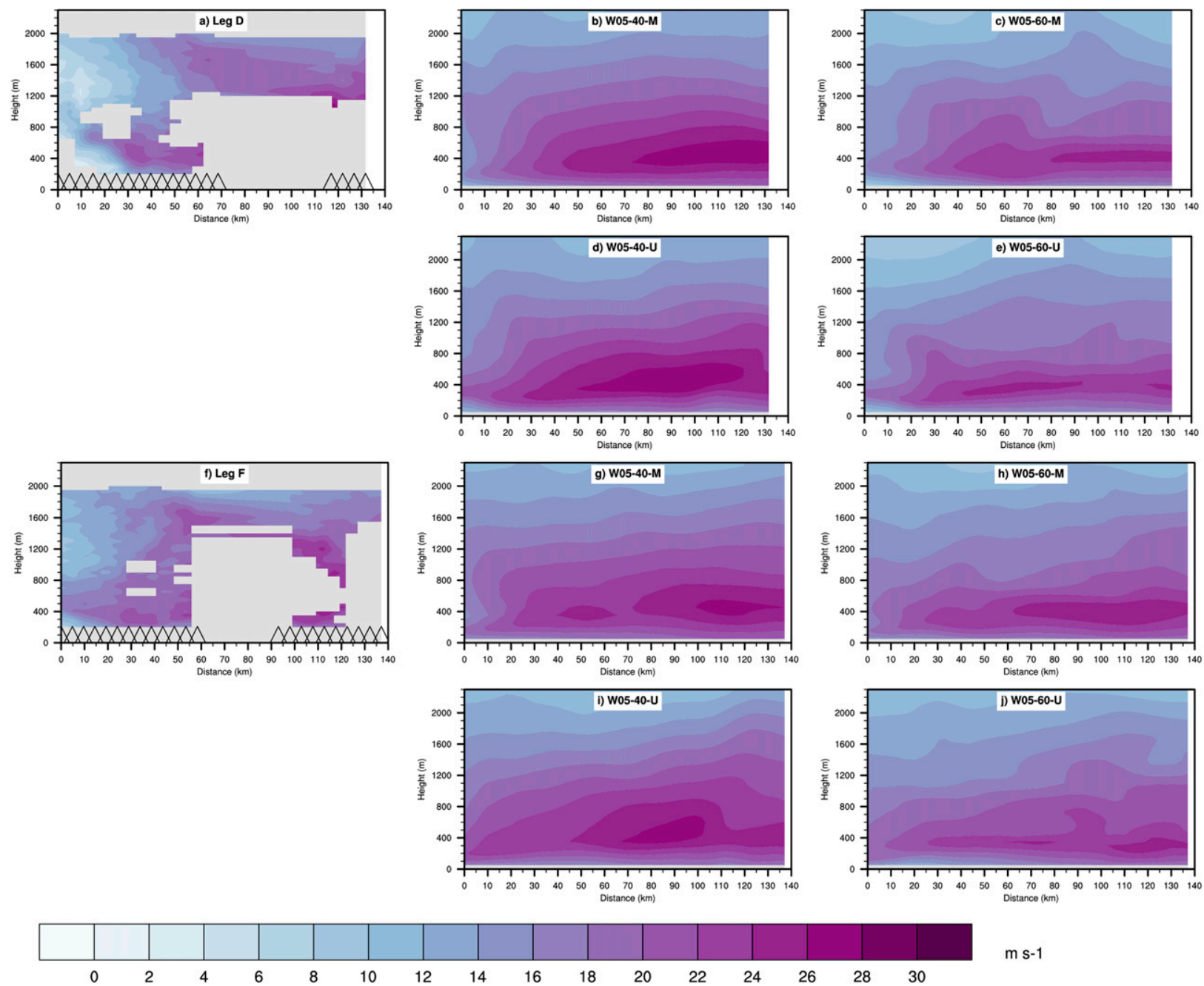

FIG. 10. Vertical cross sections of total wind speed $\left(\mathrm{m} \mathrm{s}^{-1}\right)$ from the DAWN lidar along (a) flight leg D (2026-2040 UTC) and (f) flight leg F (2059-2114 UTC). Locations of the DAWN profiles are shown as black triangles along the $x$ axis. Corresponding WRF total winds from (b),(g) W05-40-M; (c),(h) W05-60-M; (d),(i) W05-40-U; and (e),(j) W05-60-U. The 0-km point in each flight leg corresponds to the location nearest the coast.

vs thinner cloud) is similar for $5-50-\mathrm{km}$ grid spacing (Figs. 11b-e), decreasing grid spacing leads to the simulated cloud features become more detailed and realistic (Fig. 11b) while the larger grid spacing leads to more uniform, smoother clouds (Fig. 11e). The result of these differences is that simulations with larger grid spacing lead to more energy gain north and southwest of Iceland (supplemental Fig. S3).

The simulations with $5-\mathrm{km}$ grid spacing and both MYNN2.5 and UW PBL schemes indicate the presence of small, individual cloud features south of Iceland (Figs. 11b,f-h) that correspond to similar cloud structures in the satellite observations (Fig. 11a). These clouds may be the result of localized convection that is resolved by the higher-resolution model. Additionally, for the same vertical resolution the UW PBL tends to have clearer skies immediately west of Iceland (Figs. 11b vs $11 \mathrm{~g}$ and $11 \mathrm{f}$ vs $11 \mathrm{~h}$ ) where the satellite shows clear skies. However, for each PBL scheme the 5-km simulations with 40 vertical levels (Figs. 11b,g) still have too much cloud cover south of Iceland, and increasing vertical resolution leads to clearer conditions south of Iceland (Figs. 11f,h). As a result, the 60 level simulations for both PBL schemes have more surface energy gain southwest of Iceland (Figs. 11i vs $11 \mathrm{j}$ and $11 \mathrm{k}$ vs 111) where the satellite shows relatively clear conditions.

\section{Discussion and conclusions}

Taken within the scope of a larger NASA-sponsored Polar Winds field campaign, this paper presents the first airborne DWL observations of a summertime barrier 

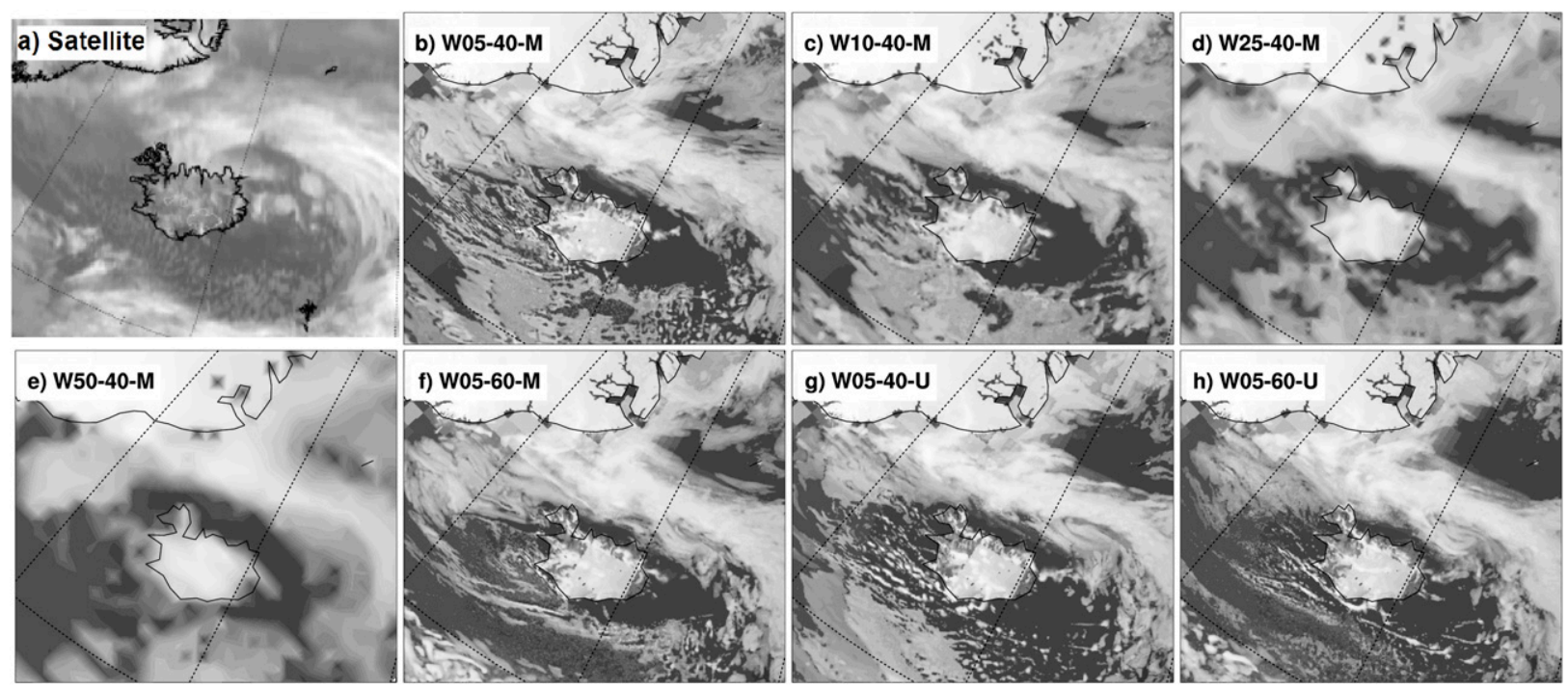

SEVIRI hitamynd:
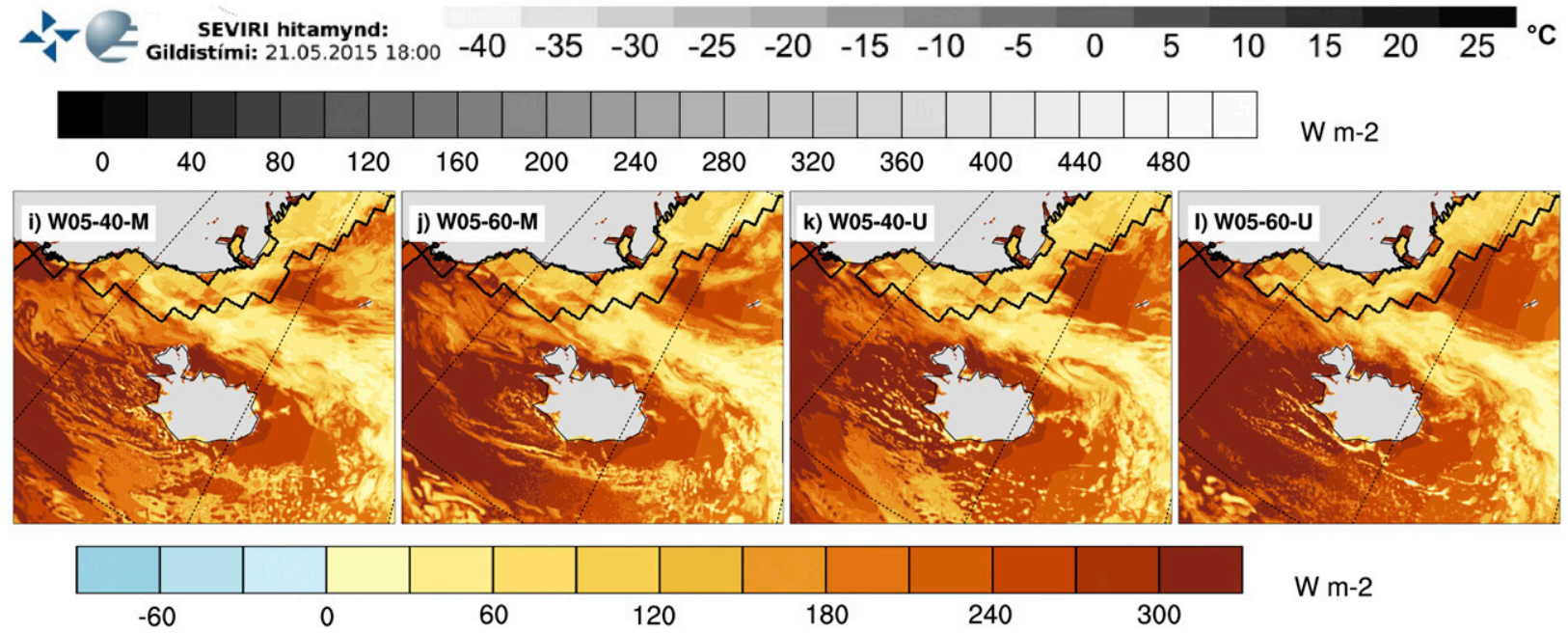

FIG. 11. 1800 UTC 21 May (a) EUMETSAT and NOAA satellite brightness temperature $\left({ }^{\circ} \mathrm{C}\right)$ provided by the Icelandic Met Office. Upward shortwave radiation at the top of the atmosphere $\left(\mathrm{W} \mathrm{m}^{-2}\right.$ ) from simulations (b) W05-40-M, (c) W10-40-M, (d) W25-40-M, (e) W50-40-M, (f) W05-60-M, (g) W05-40-U, and (h) W05-60-U. Net radiation at the surface (longwave + shortwave, with positive indicating surface energy gain) (i) W05-40-M, (j) W05-60-M, (k) W05-40-U, and (l) W05-60-U. Land points in WRF have been masked and black lines indicate the extent of the sea ice edge provided by ERA-I for the net radiation figures.

wind that occurred as a synoptic cyclone transited northeastward along the southeastern Greenland coast and eventually east of Iceland.

On 21 May 2015, DAWN profiles reveal that the barrier jet is relatively slender near the coast but broadens and speeds up with distance from the coast (Fig. 5), and the DWL profiles in the lowest $2 \mathrm{~km}$ had an average negative bias of $-0.38 \mathrm{~m} \mathrm{~s}^{-1}$, an RMSD of $1.72 \mathrm{~m} \mathrm{~s}^{-1}$, and a correlation of 0.91 compared to the dropsondes D2-D5 (Table 2). The maximum barrier jet speed was $20-25 \mathrm{~m} \mathrm{~s}^{-1}$ near $300 \mathrm{~m}$ MSL (Fig. 4), which is weaker by $5-10 \mathrm{~m} \mathrm{~s}^{-1}$ than the winter barrier winds observed during GFDex (Petersen et al. 2009) Compared to the DAWN profiles, GFDex shows smoother barrier wind fields (Petersen et al. 2009; Renfrew et al. 2009), but these observations took place over larger spatial scales $(\sim 150-250 \mathrm{~km})$ and with dropsondes spaced $\sim 40 \mathrm{~km}$ apart, so this study is the first to reveal smallerscale $(\sim 10 \mathrm{~km})$ features present within a mesoscale barrier jet. In some cases, the DAWN DWL signal was able to pass through the clouds and measure winds below [Fig. 4 (L4); Fig. 5 (legs C, D, F)]. Thus, DAWN and other airborne DWL provide a useful tool on aircraft campaigns that can provide high horizontal resolution and near-continuous observations of small-scale wind features and variability even in the presence of clouds.

In this study we are able to separate the impacts of increasing horizontal and vertical resolution on 
simulated mesoscale winds and clouds. Compared to the ASCAT satellite $10-\mathrm{m}$ wind field, simulations at $5 \mathrm{~km}$, compared to those with higher horizontal grid spacing, have the lowest RMSD and better barrier jet shape, placement, and wind speeds (Figs. 6 and 7). Compared to the dropsondes we found that increasing horizontal resolution alone did not result in better representation of the barrier jet or near surface temperature structure (Figs. 8 and 9; Table 3). Instead, increasing vertical resolution is necessary to improve the $10-\mathrm{m}$ spatial winds compared to ASCAT (Table 3; RMSD decreases by $\left.0.11 \mathrm{~m} \mathrm{~s}^{-1}\right)$, produce better near-surface $(<500 \mathrm{~m} \mathrm{MSL})$ temperature and wind speed profiles (Fig. 8), and better capture barrier jet speed and shape along DAWN flight legs (Fig. 10). These results are not surprising given that steep terrain is crucial to force wintertime barrier winds during synoptic situations similar to that observed on 21 May (Harden and Renfrew 2012), and using both high vertical and horizontal resolution are necessary to simulate flow interactions with this type of terrain. Yet even simulations with 5 -km horizontal resolution and 60 vertical levels are not able to capture all the observed small-scale variability. Given its effective resolution of $7 \Delta x$ (Skamarock 2004), WRF would need a minimum horizontal resolution of $0.7-1.4 \mathrm{~km}$ to capture the $5-10-\mathrm{km}$ features observed and likely higher vertical resolution as well. Further analysis exploring how small-scale features impact cloud structure or turbulent fluxes is needed to assess the impact on the surface energy budget.

The 5-km simulations are all able to simulate small, individual cloud features south of Iceland that are similar to those seen in the satellite observations, but using the UW PBL scheme with high vertical resolution is necessary for also capturing observed clear skies (Fig. 11). The individual cloud features appear to be spatially distinct convective plumes rather than large stratiform clouds. This indicates the importance of simulating "gray zone" atmospheric processes like convection, which is becoming resolved at $5-\mathrm{km}$ horizontal grid spacing and best simulated with high vertical resolution. Further work should be done to evaluate the impact of these types of realistic convective processes both on radiative surface fluxes in summer and turbulent surface fluxes in winter since both will strongly impact the surface energy budget and resulting ocean heat content or sea ice melt.

The two PBL schemes tested-MYNN2.5 and UWboth simulate realistic barrier jets, but we found that the UW scheme was slightly better in simulating jet wind speeds and shapes, as well as temperature inversions aloft (Figs. 8 and 9) and better at capturing the jet shapes along the DAWN flight legs (Fig. 10). However, we did find the localized slow wind speed pockets (Figs. 6 and 7) to be a potential concern. Early in the simulations (e.g., 2000 UTC 20 May, shown in supplemental Fig. S4, which is before our focus period) these localized regions of slow wind speed are more distinct for the 5-km horizontal grid spacing and present at both vertical resolutions. Because these pockets become less distinct as the simulation progresses, they may be related to spin up for the UW scheme, which may benefit from a spinup time longer than $12 \mathrm{~h}$. Alternately, because at $10-\mathrm{km}$ horizontal resolution the features are less distinct, perhaps these are small, instantaneous, turbulent features that could be removed through spatial or temporal averaging. Further work with the UW PBL scheme at high resolution should be done to understand this behavior better. Both PBL schemes are nonlocal and predict total kinetic energy (TKE) within the PBL, but few studies have evaluated the UW scheme against other PBL schemes (Cohen et al. 2015). Because the UW scheme was developed specifically for climate models and marine regions (Bretherton and Park 2009) and performed well in our analysis of the barrier wind event we recommend further investigation of the UW PBL scheme performance in high-latitude regions, particularly over sea ice and cold polar oceans. Further comparisons should include comparison to other PBL schemes as well as observations of winds and turbulent fluxes, which were not observed during this campaign.

Barrier jets in the Denmark Strait are a common wintertime occurrence (Harden et al. 2011), but little is known about summertime barrier wind events such as the one evaluated here. Because the synoptic conditions were similar to those during winter barrier jets it is likely the forcing mechanisms are similar, so this study can help inform how to best model the wintertime barrier jets and resulting heat fluxes that strongly impact the ocean. Additionally, because barrier flow necessarily has an upslope (onshore) flow component, these types of events could be related to summertime Greenland ice sheet melt because they could provide a source of lowlevel moisture and clouds along the southeast coast, the presence of which have been linked to extreme melting events (Bennartz et al. 2013; Neff et al. 2014). A deeper understanding of summer barrier wind events is also important for maritime safety in the region and it would be useful to develop a climatology to understand how common these events are and how the magnitude compares to analogous winter events.

Acknowledgments. DAWN and dropsonde data are provided courtesy of Simpson Weather Associates, who were supported by NASA and NASA LaRC under Contract NNL14AA14C. Numerical simulations were 
supported by the U.S. Department of Energy (DOE) Grants DE-SC0006178 and DE-SC0014853, and the Department of Defense High Performance Computing Modernization Program (DOD/HPCMP) provided computational resources. Data are available from the authors upon request. Thanks to three anonymous reviewers who provided insight that improved this manuscript.

\section{REFERENCES}

Bacon, S., W. J. Gould, and Y. Jia, 2003: Open-ocean convection in the Irminger Sea. Geophys. Res. Lett., 30, 1246, doi:10.1029/ 2002 GL016271.

Barstad, I., and S. Grønås, 2005: Southwesterly flows over southern Norway-Mesoscale sensitivity to large-scale wind direction and speed. Tellus, 57A, 136-152, doi:10.1111/j.1600-0870.2005.00112.x.

Bennartz, R., and Coauthors, 2013: July 2012 Greenland melt extent enhanced by low-level liquid clouds. Nature, 496, 83-86, doi:10.1038/nature12002.

Berg, P., R. Döscher, and T. Koenigk, 2013: Impacts of using spectral nudging on regional climate model RCA4 simulations of the Arctic. Geosci. Model Dev., 6, 849-859, doi:10.5194/ gmd-6-849-2013.

,-- , and 2016: On the effects of constraining atmospheric circulation in a coupled atmosphere-ocean Arctic regional climate model. Climate Dyn., 46, 3499-3515, doi:10.1007/s00382-015-2783-y.

Bourke, R. H., and R. P. Garrett, 1987: Sea ice thickness distribution in the Arctic Ocean. Cold Reg. Sci. Technol., 13, 259280, doi:10.1016/0165-232X(87)90007-3.

Bretherton, C. S., and S. Park, 2009: A new moist turbulence parameterization in the Community Atmosphere Model. J. Climate, 22, 3422-3448, doi:10.1175/2008JCLI2556.1.

Bromwich, D. H., A. B. Wilson, L.-S. Bai, G. W. K. Moore, and P. Bauer, 2016: A comparison of the regional Arctic System Reanalysis and the global ERA-Interim Reanalysis for the Arctic: The Arctic System Reanalysis. Quart. J. Roy. Meteor. Soc., 142, 644-658, doi:10.1002/qj.2527.

Cassano, J. J., M. Higgins, and M. Seefeldt, 2011: Performance of the Weather Research and Forecasting (WRF) Model for month-long pan-Arctic simulations. Mon. Wea. Rev., 139, 3469-3488, doi:10.1175/MWR-D-10-05065.1.

— System Model (RASM): Near surface atmospheric climate sensitivity. J. Climate, doi:10.1175/JCLI-D-15-0775.1, in press.

Cohen, A. E., S. M. Cavallo, M. C. Coniglio, and H. E. Brooks, 2015: A review of planetary boundary layer parameterization schemes and their sensitivity in simulating southeastern U.S. cold season severe weather environments. Wea. Forecasting, 30, 591-612, doi:10.1175/WAF-D-14-00105.1.

Copernicus Marine Service Products, 2016: ASCAT: Global ocean daily gridded sea surface winds scatterometer. Copernicus Marine Service Products, accessed 9 June 2016. [Available online at http://marine.copernicus.eu/.]

de Jong, M. F., and L. de Steur, 2016: Strong winter cooling over the Irminger Sea in winter 2014-2015, exceptional deep convection, and the emergence of anomalously low SST. Geophys. Res. Lett., 43, 7106-7113, doi:10.1002/2016GL069596.

—_, H. M. van Aken, K. Våge, and R. S. Pickart, 2012: Convective mixing in the central Irminger Sea: 2002-2010. Deep-Sea Res., 63, 36-51, doi:10.1016/j.dsr.2012.01.003.
Dee, D. P., and Coauthors, 2011: The ERA-Interim reanalysis: Configuration and performance of the data assimilation system. Quart. J. Roy. Meteor. Soc., 137, 553-597, doi:10.1002/ qj.828.

Dörnbrack, A., M. Weissman, S. Rahm, O. Reitebuch, R. Simmet, R. Busen, and H. Ólafsson, 2004: Wind lidar observations in the lee of Greenland. 11th Conf. on Mountain Meteorology, Bartlett, NH, Amer. Meteor. Soc. [Available online at https://ams. confex.com/ams/11Mountain/webprogram/Paper77231.html.]

Doyle, J. D., and M. A. Shapiro, 1999: Flow response to large-scale topography: The Greenland tip jet. Tellus, 51A, 728-748, doi:10.1034/j.1600-0870.1996.00014.x.

DuVivier, A. K., and J. J. Cassano, 2013: Evaluation of WRF Model resolution on simulated mesoscale winds and surface fluxes near Greenland. Mon. Wea. Rev., 141, 941-963, doi:10.1175/MWR-D-12-00091.1.

$\longrightarrow$, and - 2015: Exploration of turbulent heat fluxes and wind stress curl in WRF and ERA-Interim during wintertime mesoscale wind events around southeastern Greenland. J. Geophys. Res. Atmos., 120, 3593-3609, doi:10.1002/2014JD022991.

- — A. P. Craig, J. Hamman, W. Maslowski, B. Nijssen, R. Osinski, and A. Roberts, 2016: Winter atmospheric buoyancy forcing and oceanic response during strong wind events around southeastern Greenland in the Regional Arctic System Model (RASM) for 1990-2010. J. Climate, 29, 975-994, doi:10.1175/JCLI-D-15-0592.1.

Eaton, B., 2011: User's guide to the Community Atmosphere Model CAM-5.1. NCAR, 38 pp. [Available online at http://www.cesm. ucar.edu/models/cesm1.0/cam/docs/ug5_1_1/ug.pdf.]

Glisan, J. M., W. J. Gutowski, J. J. Cassano, and M. E. Higgins, 2013: Effects of spectral nudging in WRF on Arctic temperature and precipitation simulations. J. Climate, 26, 3985-3999, doi:10.1175/JCLI-D-12-00318.1.

Greco, S., G. D. Emmitt, M. J. Kavaya, R. Kaker, J. J. Cassano, and K. M. Hines, 2016: Airborne Doppler wind lidar missions in the Arctic: Low level observations and comparison with models and other observing platforms. 20th Conf. on Integrated $\mathrm{Ob}$ serving and Assimilation Systems for the Atmosphere, Oceans, and Land Surface (IOAS-AOLS), New Orleans, LA, Amer. Meteor. Soc., 670. [Available online at https://ams.confex.com/ ams/96Annual/webprogram/Paper289821.html.]

Harden, B. E., and I. A. Renfrew, 2012: On the spatial distribution of high winds off southeast Greenland. Geophys. Res. Lett., 39, L14806, doi:10.1029/2012GL051958.

, — _ and G. N. Petersen, 2011: A climatology of wintertime barrier winds off southeast Greenland. J. Climate, 24, 47014717, doi:10.1175/2011JCLI4113.1.

Hughes, M., and J. J. Cassano, 2015: The climatological distribution of extreme Arctic winds and implications for ocean and sea ice processes. J. Geophys. Res. Atmos., 120, 7358-7377, doi:10.1002/2015JD023189.

Iacono, M. J., J. S. Delamere, E. J. Mlawer, M. W. Shephard, S. A. Clough, and W. D. Collins, 2008: Radiative forcing by long-lived greenhouse gases: Calculations with the AER radiative transfer models. J. Geophys. Res., 113, D13103, doi:10.1029/ 2008JD009944.

Icelandic Met Office, 2016: SEVIRI infrared images. Icelandic Met Office, accessed 28 July 2016. [Available online at http:// brunnur.vedur.is/myndir/seviri/2015/05/21/.]

Jiménez, P. A., J. Dudhia, J. F. González-Rouco, J. Navarro, J. P. Montávez, and E. García-Bustamante, 2012: A revised scheme for the WRF surface layer formulation. Mon. Wea. Rev., 140, 898-918, doi:10.1175/MWR-D-11-00056.1. 
Kain, J. S., 2004: The Kain-Fritsch convective parameterization: An update. J. Appl. Meteor., 43, 170-181, doi:10.1175/ 1520-0450(2004)043<0170:TKCPAU>2.0.CO;2.

Kavaya, M. J., J. Y. Beyon, G. J. Koch, M. Petros, P. J. Petzar, U. N. Singh, B. C. Trieu, and J. Yu, 2014: The Doppler Aerosol Wind (DAWN) airborne, wind-profiling coherent-detection lidar system: Overview and preliminary flight results. J. Atmos. Oceanic Technol., 31, 826-842, doi:10.1175/JTECH-D-12-00274.1.

Kristjánsson, J. E., and Coauthors, 2011: The Norwegian IPYTHORPEX: Polar lows and Arctic fronts during the 2008 Andøya Campaign. Bull. Amer. Meteor. Soc., 92, 1443-1466, doi:10.1175/2011BAMS2901.1.

Lindsay, R., M. Wensnahan, A. Schweiger, and J. Zhang, 2014: Evaluation of seven different atmospheric reanalysis products in the Arctic. J. Climate, 27, 2588-2606, doi:10.1175/ JCLI-D-13-00014.1.

Mahoney, K. M., 2016: The representation of cumulus convection in high-resolution simulations of the 2013 Colorado Front Range flood. Mon. Wea. Rev., 144, 4265-4278, doi:10.1175/ MWR-D-16-0211.1.

Moore, G. W. K., 2003: Gale force winds over the Irminger Sea to the east of Cape Farewell, Greenland. Geophys. Res. Lett., 30, 1894, doi:10.1029/2003GL018012.

_- 2012: A new look at Greenland flow distortion and its impact on barrier flow, tip jets and coastal oceanography. Geophys. Res. Lett., 39, L22806, doi:10.1029/2012GL054017.

_- and I. Renfrew, 2005: Tip jets and barrier winds: A QuikSCAT climatology of high wind speed events around Greenland. J. Climate, 18, 3713-3725, doi:10.1175/JCLI3455.1.

- , R. S. Pickart, and I. A. Renfrew, 2008: Buoy observations from the windiest location in the world ocean, Cape Farewell, Greenland. Geophys. Res. Lett., 35, L18802, doi:10.1029/ 2008 GL034845.

— I. A. Renfrew, B. E. Harden, and S. H. Mernild, 2015: The impact of resolution on the representation of southeast Greenland barrier winds and katabatic flows. Geophys. Res. Lett., 42, 3011-3018, doi:10.1002/2015GL063550.

— D. H. Bromwich, A. B. Wilson, I. Renfrew, and L. Bai, 2016: Arctic System Reanalysis improvements in topographically forced winds near Greenland. Quart. J. Roy. Meteor. Soc., 142, 2033-2045, doi:10.1002/qj.2798.

Morrison, H., and Coauthors, 2009: Intercomparison of model simulations of mixed-phase clouds observed during the ARM Mixed-Phase Arctic Cloud Experiment. II: Multilayer cloud. Quart. J. Roy. Meteor. Soc., 135, 1003-1019, doi:10.1002/ qj. 415 .

Nakanishi, M., and H. Niino, 2006: An improved Mellor-Yamada level-3 model: Its numerical stability and application to a regional prediction of advection fog. Bound.-Layer Meteor., 119, 397-407, doi:10.1007/s10546-005-9030-8.

Neff, W., G. P. Compo, F. Martin Ralph, and M. D. Shupe, 2014: Continental heat anomalies and the extreme melting of the Greenland ice surface in 2012 and 1889: Melting of Greenland in 1889 and 2012. J. Geophys. Res. Atmos., 119, 6520-6536, doi:10.1002/2014JD021470.

Nigro, M. A., J. J. Cassano, M. A. Lazzara, and L. M. Keller, 2012: Case study of a barrier wind corner jet off the coast of the
Prince Olav Mountains, Antarctica. Mon. Wea. Rev., 140, 2044-2063, doi:10.1175/MWR-D-11-00261.1.

Niu, G.-Y., and Coauthors, 2011: The community Noah land surface model with multiparameterization options (Noah-MP): 1 . Model description and evaluation with local-scale measurements. J. Geophys. Res., 116, D12109, doi:10.1029/ 2010JD015139.

Oltmanns, M., F. Straneo, H. Seo, and G. W. K. Moore, 2015: The role of wave dynamics and small-scale topography for downslope wind events in southeast Greenland. J. Atmos. Sci., 72, 2786-2805, doi:10.1175/JAS-D-14-0257.1.

Petersen, G. N., I. A. Renfrew, and G. W. K. Moore, 2009: An overview of barrier winds off southeastern Greenland during the Greenland Flow Distortion experiment. Quart. J. Roy. Meteor. Soc., 135, 1950-1967, doi:10.1002/qj.455.

Pickart, R. S., M. A. Spall, M. H. Ribergaard, G. Moore, and R. F. Milliff, 2003: Deep convection in the Irminger Sea forced by the Greenland tip jet. Nature, 424, 152-156, doi:10.1038/ nature 01729 .

Prein, A. F., and Coauthors, 2015: A review on regional convection-permitting climate modeling: Demonstrations, prospects, and challenges. Rev. Geophys., 53, 323-361, doi:10.1002/2014RG000475.

Renfrew, I. A., and Coauthors, 2008: The Greenland Flow Distortion Experiment. Bull. Amer. Meteor. Soc., 89, 1307-1324, doi:10.1175/2008BAMS2508.1.

— S. D. Outten, and G. W. K. Moore, 2009: An easterly tip jet off Cape Farewell, Greenland. I: Aircraft observations. Quart. J. Roy. Meteor. Soc., 135, 1919-1933, doi:10.1002/qj.513.

Roberts, A., and Coauthors, 2015: Simulating transient ice-ocean Ekman transport in the Regional Arctic System Model and Community Earth System Model. Ann. Glaciol., 56, 211-228, doi:10.3189/2015AoG69A760.

Sampe, T., and S.-P. Xie, 2007: Mapping high sea winds from space: A global climatology. Bull. Amer. Meteor. Soc., 88, 1965-1978, doi:10.1175/BAMS-88-12-1965.

Skamarock, W. C., 2004: Evaluating mesoscale NWP models using kinetic energy spectra. Mon. Wea. Rev., 132, 3019-3032, doi:10.1175/MWR2830.1.

- - and Coauthors, 2008: A description of the Advanced Research WRF version 3. NCAR Tech. Note NCAR/TN475+STR, 113 pp., doi:10.5065/D68S4MVH.

Våge, K., and Coauthors, 2011: The Irminger Gyre: Circulation, convection, and interannual variability. Deep-Sea Res., 58 , 590-614, doi:10.1016/j.dsr.2011.03.001.

Weisman, M. L., W. C. Skamarock, and J. B. Klemp, 1997: The resolution dependence of explicitly modeled convective systems. Mon. Wea. Rev., 125, 527-548, doi:10.1175/1520-0493 (1997) $125<0527$ :TRDOEM > 2.0.CO;2.

Weissmann, M., R. Busen, A. Dörnbrack, S. Rahm, and O. Reitebuch, 2005: Targeted observations with an airborne wind lidar.J. Atmos. Oceanic Technol., 22, 1706-1719, doi:10.1175/ JTECH1801.1.

Yu, X., and T.-Y. Lee, 2010: Role of convective parameterization in simulations of a convection band at grey-zone resolutions. Tellus, 62A, 617-632, doi:10.1111/j.1600-0870.2010.00470.x. 